\title{
Key Technologies and Instrumentation for Subsurface Exploration of Ocean Worlds
}

\author{
Bernd Dachwald $^{1}(\mathbb{D})$ Stephan Ulamec ${ }^{2}(D)$ Frank Postberg $^{3}(D)$ Frank Sohl $^{4}(D)$ \\ Jean-Pierre de Vera ${ }^{4}$ - Christoph Waldmann ${ }^{5}$ (D) Ralph D. Lorenz ${ }^{6}$ (D) \\ Kris A. Zacny ${ }^{7}$ Hugo Hellard ${ }^{4}(D)$ Jens Biele $^{2}(D) \cdot$ Petra Rettberg $^{8}(D)$
}

Received: 15 July 2019 / Accepted: 16 June 2020 / Published online: 29 June 2020

(C) The Author(s) 2020

\begin{abstract}
In this chapter, the key technologies and the instrumentation required for the subsurface exploration of ocean worlds are discussed. The focus is laid on Jupiter's moon Europa and Saturn's moon Enceladus because they have the highest potential for such missions in the near future. The exploration of their oceans requires landing on the surface, penetrating the thick ice shell with an ice-penetrating probe, and probably diving with an underwater vehicle through dozens of kilometers of water to the ocean floor, to have the chance to find
\end{abstract}

Ocean Worlds

Edited by Athena Coustenis, Tilman Spohn, Rafael Rodrigo, Kevin P. Hand, Alexander Hayes, Karen Olsson-Francis, Frank Postberg, Christophe Sotin, Gabriel Tobie, Francois Raulin and Nicolas Walter

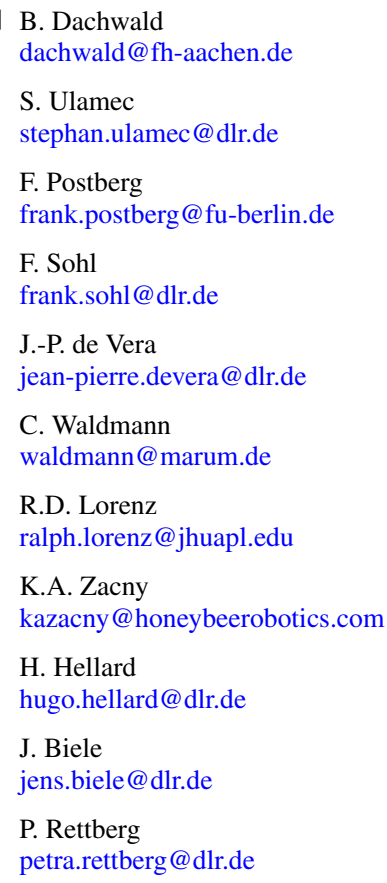


life, if it exists. Technologically, such missions are extremely challenging. The required key technologies include power generation, communications, pressure resistance, radiation hardness, corrosion protection, navigation, miniaturization, autonomy, and sterilization and cleaning. Simpler mission concepts involve impactors and penetrators or - in the case of Enceladus - plume-fly-through missions.

Keywords Subsurface access · Melting probes · Drilling probes · Impactors · Penetrators · Underwater vehicles · Plume-sampling · In-situ instrumentation · Europa · Enceladus · Icy moons $\cdot$ Ocean worlds

\section{Introduction}

Many bodies in the outer solar system are expected to harbor liquid oceans beneath their icy shells (Hussmann et al. 2006; Nimmo and Pappalardo 2016). Measurements in combination with analytical calculations and computer modelling suggest that their physical and chemical parameters (overlying ice thickness, depth, pressure, temperature, chemistry, contact to silicates, etc.) are very diverse and so is probably their potential to harbor life. The diversity of life found through the exploration of analogue extreme environments on Earth like Antarctic subglacial lakes and deep-sea hydrothermal vents can guide our imagination of what we may expect in such alien oceans. This chapter focuses on Jupiter's moon Europa and Saturn's moon Enceladus because they have the highest potential for subsurface exploration missions in the near future (Table 1 lists their main physical and orbital properties). Having rocky silicate seafloors in contact with saltwater oceans, both moons may have the potential to host the kinds of water-rock interactions that can sustain chemosynthesis - life independent of sunlight - which would open up a whole new dimension of habitability in the solar system and, indeed, in all other star systems.

To land a substantial amount of hardware (i.e., in the order of a few hundred kilograms up to a few metric tons), on an icy moon is already very hard. The required changes in orbital energy and thus velocity (termed $\Delta V$ in spaceflight mechanics) to land on the surface of Europa or Enceladus is so enormous that either multiple rocket launches with in-orbit assembly, or very advanced high-power and high-specific-impulse propulsion systems, or many timeconsuming gravity assist maneuvers are required (during the interplanetary cruise phase, they can be performed at the planets; after capture in the Jovian or Saturnian system, they

1 Faculty of Aerospace Engineering, FH Aachen University of Applied Sciences, Hohenstaufenallee 6, 52076 Aachen, Germany

2 Space Operations and Astronaut Training - MUSC, German Aerospace Center (DLR), Linder Höhe, 51147 Cologne, Germany

3 Institute of Geological Sciences, FU Berlin, Malteserstr. 74-100, 12249 Berlin, Germany

4 Institute of Planetary Research, German Aerospace Center (DLR), Rutherfordstr. 2, 12489 Berlin, Germany

5 MARUM, University of Bremen, Leobener Str. 8, 28359 Bremen, Germany

6 Applied Physics Lab, Johns Hopkins University, 11100 Johns Hopkins Road, Laurel, MD 20723, USA

7 Honeybee Robotics, 398 W Washington Blvd., Pasadena, CA 91103, USA

8 Institute of Aerospace Medicine, German Aerospace Center (DLR), Linder Höhe, 51147 Cologne, Germany 
Table 1 Europa's and Enceladus' physical and orbital properties (data from NASA's National Space Science Data Center, http://nssdc.gsfc.nasa. gov/)

\begin{tabular}{lll}
\hline Parameter & Europa & Enceladus \\
\hline Mean radius [km] & 1560.8 & 252.1 \\
Mass [kg] & $4.800 \times 10^{22}$ & $1.080 \times 10^{20}$ \\
Equatorial surface gravity [m/s $\left.{ }^{2}\right]$ & 1.314 & 0.113 \\
Mean density [g/cm $\left.{ }^{3}\right]$ & 3.013 & 1.609 \\
Escape velocity [km/s] & 2.025 & 0.239 \\
Semi-major axis [km] & 670900 & 237948 \\
Orbital period [d] & 3.5512 & 1.3702 \\
Orbital eccentricity [-] & 0.009 & 0.0047 \\
Mean solar distance [au] & 5.204 & 9.583 \\
Mean solar radiation flux $\left[\mathrm{W} / \mathrm{m}^{2}\right]$ & 50.5 & 14.9 \\
\hline
\end{tabular}

can be performed at the larger moons of the Jovian or Saturnian system). After landing on an outer solar system's moon, power generation is a problem due to the large distance from the Sun that precludes the usage of solar power (also, solar cells are susceptible to rapid degradation by high radiation doses). Consequently, from an engineering point of view, Europa and Enceladus have to be considered as almost-zero-energy environments that require an own "imported" power source. Given such constraints, it is even harder to penetrate many kilometers of ice (which is already hard with huge power generators on Earth). If life has arisen within an ocean world, its widest distribution is probably found at the ocean floor (as in subglacial lakes on Earth), where energy and nutrients from the moon's silicate core are most readily available, but the ice-ocean interface may also be a good place to search for life. Therefore, after penetration into such an exo-ocean is achieved, an underwater vehicle has to dive dozens of kilometers deep to find life that is probably not equally distributed over the seafloor so that the vehicle probably has to explore hundreds of square kilometers. Note that even on Earth, hydrothermal seafloor vents were only found quite recently (Corliss et al. 1979). The vast majority of vents that are predicted to occur have not yet been located. The best analogue to what is happening on Enceladus, the Von Damm hydrothermal field (McDermott et al. 2015), was actually discovered more recently than Cassini has first imaged the plumes at Enceladus. When first discovered, there was no known vent-site on Earth that could account for both the high $\mathrm{Si}$ and high $\mathrm{H}_{2}$ measured by Cassini at the inferred temperatures of $\approx 100{ }^{\circ} \mathrm{C}$. It is evident that many technical challenges belong more to the field of oceanographic engineering than space engineering, so that interdisciplinary collaboration will be a key for mission success, as well as the early participation of scientists that work on analogous extreme terrestrial environments like subglacial lakes (Siegert et al. 2011, 2016).

\section{Environmental Conditions and Engineering Constraints}

The present knowledge of the surface environments of icy satellites with putative subsurface oceans has grown considerably over the past three decades by dedicated spacecraft observations and ground-based telescope surveys. There is geophysical evidence from Galileo and Cassini observations that at least Europa, Ganymede, Callisto, Enceladus and Titan harbor global oceans. Of particular interest for future in-situ lander missions, however, are the surfaces of Europa and Enceladus, to study in detail the physical and chemical exchange processes with their deep interiors (Hendrix et al. 2019). From the absence of larger craters, it can be deduced that both the surface of Europa and the south polar terrain of Enceladus must 
be geologically young (Bierhaus et al. 2009; Kirchoff et al. 2018). In contrast to Ganymede, Callisto and Titan, the subsurface oceans on Europa and Enceladus are believed to be in contact with a rocky seafloor (Hussmann et al. 2006), thereby increasing their potential for habitability. The surface of Europa and the south polar terrain of Enceladus are subject to intense tectonic resurfacing, resulting in prominent geological surface features, e.g., double ridges and networks of sub-parallel cracks, fractures, and faults. Surface deformation features such as tectonic grabens are frequently used to characterize the subsurface properties and thermal state at their time of formation (Prockter et al. 2010; Stephan et al. 2013).

Lacking a dense atmosphere, the near-surface layers of icy satellites are persistently disrupted by impact gardening due to hypervelocity collisions with minor bodies and meteoroids, and further eroded by photolysis due to intense ultraviolet radiation and radiolysis due to high-energy neutral ion and particle bombardment. The reflectance spectra in the outer solar system are clearly dominated by crystalline water ice (Dalton 2010). Possible exceptions of amorphous ice are found on Ganymede and Europa, where the crystalline structure of water ice will be disrupted due to the intense radiation caused by Jupiter's corotating magnetosphere (Dalton 2010). Additionally, the surfaces of geologically active icy satellites like Enceladus, Europa, and Triton are currently modified by the deposition of condensates released from active venting plumes (Southworth et al. 2015, 2019). Cassini VIMS observations indicate that particle sizes are strongly correlated with geologic features and surface ages. Whereas the smallest particles were found in old densely cratered terrains subject to impact gardening, the largest particles with ice grain sizes of about $200 \mu \mathrm{m}$ are concentrated in immediate vicinity of venting plumes in the tiger-stripe regions (Jaumann et al. 2008). The occurrence of hydrated salts in the vicinity of Enceladus or of salt-rich surface deposits on Europa clearly indicates the presence of liquid subsurface reservoirs and water-rock exchange in aqueous environments on these bodies (Postberg et al. 2009, 2011b; Trumbo et al. 2019).

The surface temperature on Europa ranges between 86 and $132 \mathrm{~K}$, whereas there is a broad range of observed surface temperatures on Enceladus. These may vary from 33 to $85 \mathrm{~K}$ depending on insolation, 120 to $160 \mathrm{~K}$ at hot spots, and peak at about $200 \mathrm{~K}$ in the tiger-stripe regions (Dalton 2010; Goguen et al. 2013). The surface brightness of Enceladus is related to intense resurfacing due to the deposition of plume particles. For example, Europa's ice shell is most likely a few to a few tens of kilometers thick but investigations of the equilibrium shell thickness from a balance between tidal heating and heat transport have yielded a wide range of possible solutions, because the (uncertain) ice viscosity has a strong effect on both tidal heating and heat transport (Schubert et al. 2009; Nimmo and Pappalardo 2016). Since the cold surfaces of icy satellites are porous and heavily fractured, it is generally assumed that yield strength is controlled by frictional sliding at shallow depth and by plastic creep deformation at greater depths (Litwin et al. 2012). In between, stresses are assumed to be accommodated elastically. The transition from brittle to ductile behavior occurs at a critical sliding speed where brittle strength equals ductile strength, in analogy to a critical strain rate within bulk ice (Schulson 2013).

Owing to the low surface temperature and low gravity on small icy bodies, the brittle zone is expected to retain substantial porosity in excess of a value of 0.1 . This is significant and will strongly affect thermal diffusivity, tensile strength, acoustic and dielectric properties, vapour transport, and other key properties relevant for ice-penetrating probes (Moore et al. 2009b). The mechanical and thermophysical properties of ice are further affected by the incorporation of non-ice contaminants due to the delivery of micrometeoroids, the deposition of salty plume particles, partial melting, or volatile release and upward percolation of cryomagmas (McCord et al. 1998). Small temperature variations are sufficient to promote 
Fig. 1 Schematic cross section of Europa's outer ice shell. The vertical scale is exponentially exaggerated. The floating ice shell is assumed to be $20 \mathrm{~km}$ thick, while the depth of the ocean floor is taken as $100 \mathrm{~km}$ (adapted from Moore et al. (2009a))

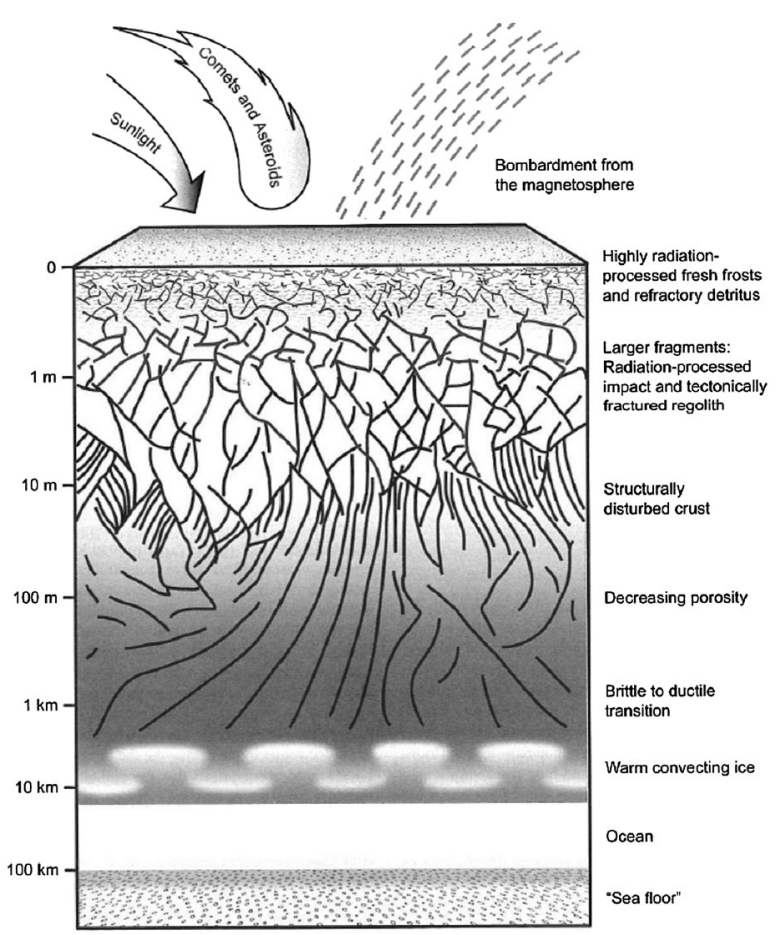

chlathrate decomposition and subsequent release of trapped gases. The presence of salts or ammonia in subsurface liquid reservoirs could cause significant melting point reduction (Kargel 1998), hence increasing viscosity at the base of the icy shell and shifting the brittleductile transition to greater depths (Durham et al. 2010). Figure 1 schematically shows the depth variation of strength across Europa's ice shell.

For Enceladus, the lower and upper limits of the average ice shell thickness are $18 \mathrm{~km}$ and $44 \mathrm{~km}$, respectively (Fig. 2) (Hemingway et al. 2018). Although most authors now agree that the ice shell is thinnest at the poles and thickest at the equator, the exact numbers are still a matter of debate. Depending on the model, numbers for the thickness of the ice crust vary between 2 and $20 \mathrm{~km}$ at the south pole and between 30 and $60 \mathrm{~km}$ at the equator. Recent investigations of microwave emission radiometry at the south polar terrain (SPT) by Le Gall et al. (2017), however, are only in agreement with an ice shell thickness of not more than $5 \mathrm{~km}$, which corresponds to an equatorial crustal thickness of about $35 \mathrm{~km}$.

The SPT on Enceladus is special in many regards. As illustrated in Fig. 3, supersonic jets of gas and ice grains penetrate the icy crust to form large cryo-volcanic plumes towering above Enceladus' south pole (Spahn et al. 2006; Hansen et al. 2006; Porco et al. 2006). Jets emerge from almost parallel cracks called tiger stripes, each about $150 \mathrm{~km}$ in length and a distance of about $35 \mathrm{~km}$ between each crustal fracture. The cracks appear to cut through the entire thickness of the ice shell tapping into the global ocean underneath (Kite and Rubin 2016; Spencer et al. 2018). From buoyancy arguments, water should fill large parts of these cracks and the water surface (or water table) should be situated at $\approx 90 \%$ of the distance from the ocean to the surface, dividing each fracture into a lower, water-filled part and an upper, vapour-filled part. From the considerations above, it seems well possible that liquid water is situated at a depth of only a few hundred meters inside the tiger-stripe fractures. The width of the water filled part of the cracks is unknown but from several models it is 


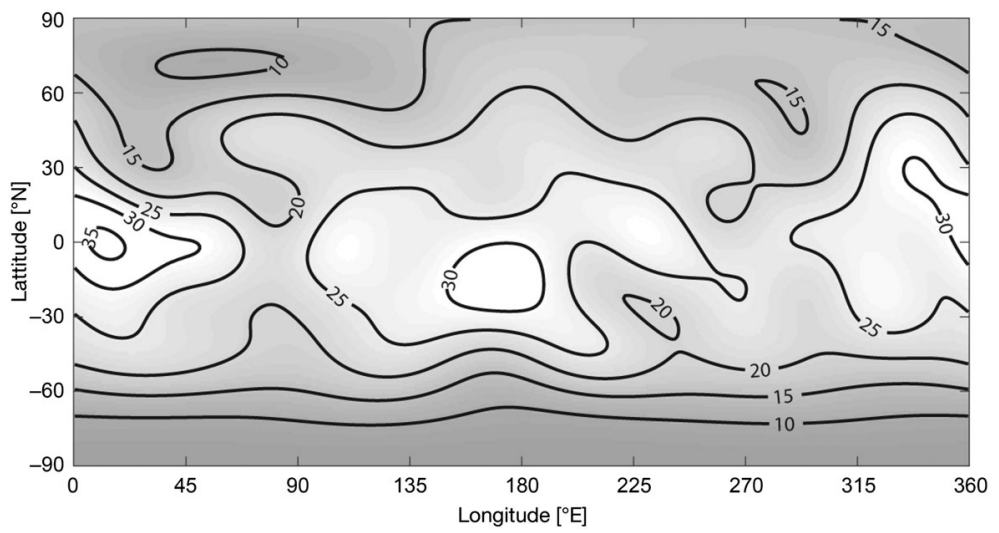

Fig. 2 Ice-shell thickness at Enceladus (assuming complete Airy compensation of all known topography), ranging from $\approx 6 \mathrm{~km}$ at the south pole to $\approx 36 \mathrm{~km}$ at the equator, with a mean thickness of $22 \mathrm{~km}$ (adapted from Hemingway et al. (2018))

estimated to be in the order of $1 \mathrm{~m}$ (Kite and Rubin 2016; Spencer et al. 2018). The exact depth of the water table is probably variable due to "flushing" from tidal flexing of the crust and can vary by tens of meters (Kite and Rubin 2016). Based on heat flow considerations, the presence of wider vapor chambers has been suggested at the water surfaces, allowing large evaporating surfaces that then narrow down again to vent channels. This geometry would provide sufficient backpressure to prevent the water from violent boiling at its triple point (Postberg et al. 2009), which would lead to immediate self-sealing of a vent. However, other authors suggest that these chambers in the ice are not required (Nakajima and Ingersoll 2016; Ingersoll and Nakajima 2016). Models agree, however, that above the water surface the average width of cracks narrows down to not more than a few tens of centimeters (Schmidt et al. 2008; Postberg et al. 2011b; Ingersoll and Nakajima 2016). The localized emergence of jets along the tiger stripes that often goes along with localized hot spots suggests that above the water surface vapor and ice grains are transported through pipes. The outflow along the fissures in between these jets appears to be much lower. Close to the surface, the widths of the outlets have been constrained to be in the order of $1 \mathrm{~m}$ (Goguen et al. 2013), indicating that vents widen again near the surface. Jets, unlike the plume, occasionally appear to turn on and off on typical time scales of years (Nimmo et al. 2014), indicating occasional opening and sealing of certain ice vents.

At the outlets, temperatures close to $200 \mathrm{~K}$ occur, probably limited by sublimation cooling (Goguen et al. 2013). An entire tiger stripe over a width of about $200 \mathrm{~m}$ is warmer than the surrounding ice by several tens of kelvins (Spencer et al. 2018). Further away from the fracture, the surface temperatures decrease quickly and reach a constant level of about $75-80 \mathrm{~K}$ about $1 \mathrm{~km}$ away from the tiger stripes. Note, that this temperature level in between tiger stripes is still a little bit higher than the surface temperature from solar heating measured at Enceladus' equator, indicating a conductive heat flow emanating from the subsurface ocean through the thinned ice shell of the entire SPT (Spencer et al. 2018).

Gas and ice grains in the Enceladean plume, at least to a greater part, is material from the subsurface ocean (Postberg et al. 2009, 2011b, 2018b,a; Waite et al. 2009, 2017). The mechanical and thermodynamic driver of the plume is evaporation of ocean water from the water table inside back-pressured vents at temperatures close to the freezing point of the salty $(\approx 1-2 \%$ salinity) and alkaline ( $\mathrm{pH} 8.5-12)$ water (Postberg et al. 2009; Hsu et al. 2015; Glein et al. 2015). An average total amount of about $300 \mathrm{~kg} / \mathrm{s}$ of water vapour (Hansen 
Fig. 3 Schematic illustrating the current knowledge of the small-scale physical and thermal structure and processes relevant to Enceladus' plume formation (from Porco et al. (2014))

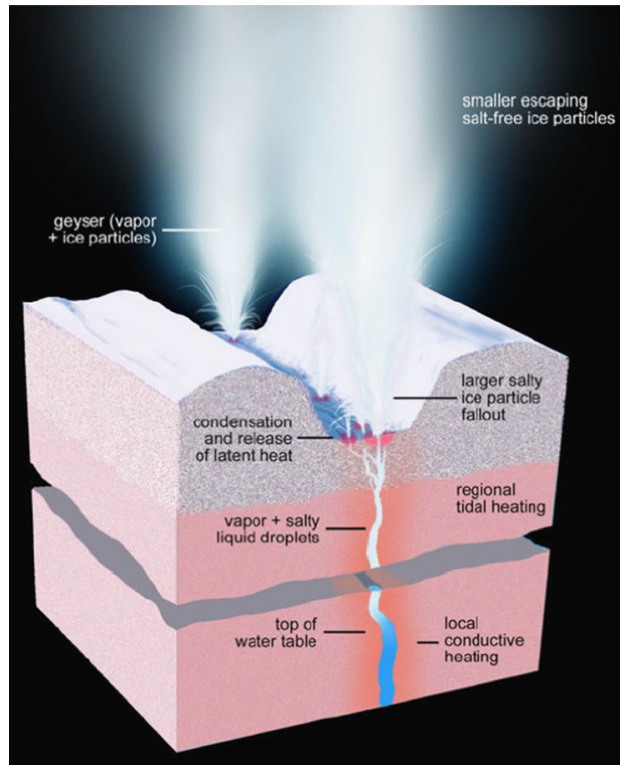

et al. 2019) escapes into the plume, setting a lower limit for the evaporative flux below. The vapour is partially redeposited onto the vents' ice walls (Ingersoll and Pankine 2010; Ingersoll and Nakajima 2016) and also partially condenses to tiny ice grains with sizes mostly below $1 \mu \mathrm{m}$ (Schmidt et al. 2008; Postberg et al. 2009, 2011b; Yeoh et al. 2015). However, a large part of the ice grains appear to be frozen ocean spray (Postberg et al. 2009, $2011 \mathrm{~b}$ ) that has undergone only minor or moderate modification by interaction with the gas phase in the ice vents (Bouquet et al. 2019; Khawaja et al. 2019).

On average, the plume emits a total mass flow of gas and icy dust of $250-350 \mathrm{~kg} / \mathrm{s}$. Estimates for the gas-to-ice ratio in the plume vary greatly, ranging from 30 to 1.5. However, the latest estimates settle around a value of 10 (Kempf et al. 2018; Postberg et al. 2018a). The plume is also known to be time-variable. The most apparent activity cycle is coupled to the moon's orbital period (Hedman et al. 2013; Nimmo et al. 2014; Ingersoll and Ewald 2017), during which the plume brightness from emitted ice grains varies by about a factor of four. The ejection speed of the gas (Hansen et al. 2008) is much larger than that of the dust grains (Schmidt et al. 2008; Hedman et al. 2009). Therefore, the gas almost completely escapes into space, whereas a large fraction $(\approx 90 \%)$ of the solid material falls back to the surface (Porco et al. 2006; Spahn et al. 2006; Kempf et al. 2018). This strongly couples plume composition and surface composition, especially at the SPT where most of the plume material is deposited (Postberg et al. 2018a). The deposition of plume fall-out as a snow layer on Enceladus' surface is expected to be about 1-10 mm/yr close to the tiger stripes, depending on the "fluffiness" of the snow layer and about an order of magnitude less at the rest of the SPT (Southworth et al. 2019). The composition of the plume and the surface is dominated by water: For the neutral gas, the water abundance is larger than $96 \%$, for dust grains, it is in the order of $99 \%$ on average (Postberg et al. 2018a). However, there are significant amounts of non-water compounds in the plume. The main non-icy compounds are sodium salts and organic material in the solid phase (Postberg et al. 2009, 2011b, 2018b) and $\mathrm{H}_{2}, \mathrm{NH}_{3}, \mathrm{CO}_{2}$ and $\mathrm{CH}_{4}$ in the gas phase (Waite et al. 2017).

The depth of the ocean layer is constrained by the diameter of Enceladus' rocky core (radius $\approx 192 \mathrm{~km}$ ) and the variable thickness of the ice shell. The numbers given above, for 
example, would yield an ocean depth of over $55 \mathrm{~km}$ at the south pole and $\approx 25 \mathrm{~km}$ at the equator. The rocky core has a surprisingly low average density of $2.3-2.5 \mathrm{~g} / \mathrm{cm}^{3}$ (Iess et al. 2014). This is best reconciled with a core porosity of about $20 \%$, giving rise to the idea of a water-percolated core (Choblet et al. 2017). Indeed, modeling indicates that such a permeable core appears to be required to explain the heat generation and dissipation from tidal friction inside the core to prevent the ocean from slow freezing over geological timescales (Choblet et al. 2017). Tidal dissipation inside a water-filled rocky core would lead to hydrothermal hot spots located at the poles at the bottom of the ocean. Indeed, compositional measurements of plume constituents (Hsu et al. 2015; Waite et al. 2017) indicate the presence of such a hot water environment at the bottom of the ocean or even inside the core (Sekine et al. 2015; Glein et al. 2018).

\section{A Stepwise Approach for the Subsurface Exploration of Ocean Worlds}

According to the study team that compiled NASA's roadmap to ocean worlds (Hendrix et al. 2019), the overarching goal of an ocean worlds exploration program is to identify such worlds, characterize their oceans, evaluate their habitability, search for life, and ultimately understand any life we may find. The study team advocates a program that subsequently focuses on (1) understanding where/why oceans are present, which allows for (2) characterizing ocean environments in these known ocean worlds. With known ocean environments it becomes important to (3) characterize their habitability and ultimately (4) search for extant life. To do this, the study team recommends Europa and Enceladus - besides Titan and Triton - as high-priority targets. This suggests a stepwise approach before sending tremendously intricate and thus expensive life-searching exo-ocean exploration missions to Europa or Enceladus. In order to better address environmental and subsurface properties, remote sensing data of possible landing sites should be acquired by using imaging, photometry, thermal and radar methods at the highest spatial and spectral resolution possible.

From a technological point of view, two approaches are generally possible for a successful exo-ocean exploration mission that includes a lander or surface station, possibly a penetrator and maybe even an underwater vehicle. Without much reflection, the simplest approach is to design a system that is able to cope with all possible environmental conditions. It can land on any surface, penetrate any kind of ice shell, no matter how thick, and submerge through any kind of ocean, no matter how deep, to find any kind of extant life, no matter how different it may be compared to life on Earth. It is easy to understand that this is not the best approach because such a system must be extremely intricate and thus enormously expensive, and such a mission would be very risky. A much better technological approach is to first characterize the relevant environments - surface, ice shell, ice-ocean interface, ocean - and then to design systems that are capable to operate in those (then known) environments with the required robustness and reliability at less cost. For example, a lander first requires multiple close spacecraft flybys or an orbiter that remotely analyzes the surface for its physical properties (porosity, dust-to-ice ratio, organics, min. and max. temperatures, radiation) and its topography down to a lander-size scale. The next mission, a lander that may already feature a short-range ice-penetration probe, then lands on the surface to study the surface and near-surface ice properties in situ. The next mission may then analyze the ice shell (temperature distribution, ice properties, obstacles) with a long-range ice-penetrating probe that may already reach and explore the ice-ocean interface (e.g. is there slush ice ore ice boulders that move with a current) and the upper ocean (currents, density, salinity, 
temperature, chemistry). An important accompanying task for all steps of exo-ocean exploration is theoretical modeling to anticipate the probable environments for the technology to work in, as well as all the different conditions for life to form and its signatures to be detected. By steering future missions toward the best target(s), modeling and the creation of a comprehensive theoretical framework can raise the probability for mission success and maximize the scientific outcome (German et al. 2019a). The obvious big disadvantage of such a stepwise approach is of course its long time scale. Given a typical flight time of 4-8 years to Jupiter and Saturn (respecting launch windows) and several years of development, this approach takes decades until mankind will reach the bottom of an exo-ocean (however, 50 years ago, Pioneer and Voyager skeptics may also have lamented that it will take decades to reach near-interstellar space and now we are there).

A first mission to characterize the ocean environment and its habitability on Europa is the Europa Clipper mission (Phillips and Pappalardo 2014), whereas a first mission to characterize the ocean environment and its habitability on Enceladus could be the proposed Enceladus Life Finder mission (Reh et al. 2016) or the Enceladus Life Signatures and Habitability mission (Eigenbrode et al. 2018), see Sects. 4.1 and 5.1.1, respectively. Lander missions to Europa and Enceladus may follow once our knowledge on their surfaces at very small scales has improved and landing risks can be reduced. Also missions to other icy moons (e.g. Triton or Titan) would help enhancing our knowledge and prepare for the challenges of surface and subsurface icy-moon exploration.

\section{Key Technologies for Access to Subsurface Material}

\subsection{Plume-Capturing}

The Cassini in-situ instruments have demonstrated that physical and chemical properties of the ocean and its habitability can be obtained via the probing of plume material during an Enceladus flyby or even by flying through the E-ring (Postberg et al. 2018a; Glein et al. 2018). Quite impressively, this goal was achieved with instruments that were by no means optimized for this task because they were designed in the early 1990s, over a decade before the discovery of the Enceladean plumes. It is obvious that analyzing plume material during a flyby with a modern and dedicated payload has an enormous potential. Although both plume components, gas and ice grains, are relevant for exploring the habitability of Enceladus ocean, complex organic material and most biosignatures are expected to reside in the ice grains (Porco et al. 2017; Postberg et al. 2018b; Khawaja et al. 2019). It is worth mentioning that the required technologies for sampling plumes at Enceladus may also be used for other moons like Europa and Triton, which may also form plumes (Sparks et al. 2017; Soderblom et al. 1990).

A major caveat in plume sampling is the sparseness of icy plume material. Cassini images, taken from very high solar phase angles (since the plume is invisible in reflected light), can be quite misleading because the plume is actually extremely tenuous. The current best estimates yield an average total emission rate for ice grains of about $20-25 \mathrm{~kg} / \mathrm{s}$ (Kempf et al. 2018; Southworth et al. 2019), which might vary by a factor of two up and down, depending on Enceladus' orbital position (Hedman et al. 2013; Nimmo et al. 2014). This material is distributed over a plume volume of $>10^{10} \mathrm{~km}^{3}$, which yields $<100$ particles $/ \mathrm{m}^{3}$ (each only $\mu \mathrm{m}$-sized). For plume-sampling, it is advantageous that the number density of ice grains and their average size both increase closer to the surface (Hedman et al. 2009; Postberg et al. 2011b; Southworth et al. 2019; Kempf et al. 2018), so that a close flyby would 
drastically increase the collectable mass of ice grains. However, even optimistic calculations predict a sample mass of $1.6 \mathrm{mg}$ (or $1.6 \mathrm{~mL}$ ) per $\mathrm{m}^{2}$ collector area at a single low-altitude flyby $(25 \mathrm{~km})$ over the most active part of Enceladus' SPT (Guzman et al. 2019). This material will contain on average less than $0.5 \%$ of organic material in total (Postberg et al. 2018a), so that even under optimal circumstances, less than $10 \mu \mathrm{g}$ of organic material would be sampled per $\mathrm{m}^{2}$ of collector area and per flyby. Multiple flybys allow the collection of more material (Massarweh and Cappuccio 2020).

Plume-sample return mission concepts like LIFE by Tsou et al. (2012) and several concepts studied by Sekine et al. (2014) mention the importance of the flyby velocity for the intact collection of plume materials. They propose to minimize the Enceladus flyby velocity for a Saturn orbiter to about 3-4 km/s. The better - though more costly - scenario, which would guarantee collection of unaltered plume samples, would require the spacecraft to go into orbit around Enceladus, thereby achieving much lower plume fly-through velocities of less than about $0.2 \mathrm{~km} / \mathrm{s}$. In both cases, the samples would have to be cyro-cooled on the way to Earth.

The most successful instruments onboard Cassini were its in-situ mass spectrometers: the Cosmic Dust Analyser CDA (Srama et al. 2004), analyzing the composition of individual plume ice grains, and the Ion and Neutral Mass Spectrometer (INMS) (Waite et al. 2004), analyzing the composition of the plume gases. These instruments were not limited by the small amount of vapor and ice grains present in the plume. They not only gave the first solid evidence for the existence of a subsurface ocean (Postberg et al. 2009) but further constrained properties like temperature, salinity, and pH (Postberg et al. 2009, 2011b; Glein et al. 2015; Hsu et al. 2015). Ultimately, these instrument inferred the presence of hydrothermal activity and could even specify similarities to the serpentenizing, alkaline hydrothermal vents on Earth, like Lost City (Hsu et al. 2015; Tobie 2015; Sekine et al. 2015; Waite et al. 2017; Glein et al. 2018) or the Von Damm hydrothermal field (Waite et al. 2017; Glein et al. 2018; McDermott et al. 2015).

Based on this success, a very similar combination of two in-situ mass spectrometers, the Surface Dust Analyzer (SUDA) and the Mass Spectrometer for Planetary Exploration (MASPEX) was selected for the payload of the Europa Clipper, a space mission targeted to investigate the habitability of Europa's subsurface ocean with a series of at least 45 close flybys. Although the original goal of the two instruments was to investigate vapor (MASPEX) and ice grains (SUDA) lifted from the Europan surface (Postberg et al. 2011a), evidence recently solidified that Europa hosts plumes that might be similar to those on Enceladus (Roth et al. 2014; Sparks et al. 2016, 2017; Jia et al. 2018) and could be probed by the two mass spectrometers aboard the Europa Clipper. Building on the precise knowledge about how these instruments operate in Enceladus' plume, a similar combination of mass spectrometers was proposed for two Enceladus missions concepts, one by NASA (Enceladus Life Finder, ELF) and one by ESA (Explorer of Enceladus and Titan, E2T), in 2015 and 2016, with vastly advanced successors of the Cassini instruments. The goal was to greatly enhance the knowledge about Enceladus' hydrothermal ocean chemistry, its habitability, and even the presence of life (Lunine et al. 2015; Reh et al. 2016; Mitri et al. 2018).

While the gas mass spectrometers of the aforementioned missions (Cassini and Europa Clipper) and mission concepts (ELF and E2T) use electron ionization to ionize the plume gases for analysis by mass spectrometry, the dust analyzers use the method of impact ionization. There, the kinetic energy of a $\mu \mathrm{m}$-sized ice grain hitting a metal target plate at speeds in excess of $1 \mathrm{~km} / \mathrm{s}$ is used to not only vaporize but to ionize a substantial fraction of the ice grain (Srama et al. 2004). The ions that have formed in the impact cloud are then analyzed by time-of-flight mass spectrometry yielding the mass spectrum of each individual ice grain 
that is encountered by the instrument. Analogue experiments show that these instruments can detect and quantify trace amounts (parts per billion quantities) of biogenic material like amino acids, peptides, and fatty acids, if present in an ice grain (Klenner et al. 2020a,b).

An alternative mission concept is the collection of plume material with a large funnel in an Enceladus orbit or during a very slow flyby. The sampled material is melted and subsequently analyzed by a suite of in-situ instruments. Such a mission, the Enceladus Life Signatures and Habitability (ELSAH), was proposed to NASA in 2017 as an alternative to ELF (Eigenbrode et al. 2018). Although the details of this proposal were not made public, it requires a quite sophisticated technique to collect unaltered plume material in sufficient quantities for the different analytical instruments.

As outlined above, there will be only about $1 \mathrm{~mL}$ of water collected by an area of $1 \mathrm{~m}^{2}$ during a single flyby, even on a low altitude plume crossing. Therefore, all instrument concepts that are based on a collection of plume material that is subsequently chemically analyzed have to deal with small sample quantities. In Sect. 5.1.1, we present an instrument suite capable to determine the presence of life, in case the sampling problem is solved.

\subsection{Impactors and Penetrators}

The function of an impactor is to interrogate a planetary surface by applying kinetic energy. This is usually with the intent to launch or vaporize material for optical observation, as in the LCROSS experiment at the Moon (Schultz et al. 2010), or for in-situ analysis or sample collection, as in the proposed Ice Clipper mission to Europa (McKay 2002). An impact may excavate a crater that exposes subsurface material for remote observation and that allows to assess surface properties via cratering physics and chemistry. An additional function of an impactor may be to act as a known seismic source to probe a planetary body's interior structure, like the Saturn IVB stages of the Apollo missions 13-17 did for the Moon (Latham et al. 1970). In principle, an impactor can be a simple inert mass, although in some cases, as in the Deep Impact mission (A'Hearn et al. 2005), delivery to the target may require onboard guidance and propulsion systems, as in the Double Asteroid Redirection Test (DART) presently in development (Cheng et al. 2016). Impacts can be at energies below the hypervelocity regime, like the balance masses shed by the Mars Science Laboratory Curiosity during its entry (these lumps of tungsten caused small craters (Bierhaus et al. 2013)) but are more typically at velocities of many kilometers per second. These higher energies, typically given by the arrival conditions, such that the impactor can be simple, may be needed to launch material from the surface (typically ejecta is launched at about half the impact speed), and are necessary if the intent is to ionize material for spectroscopic observation (as in LCROSS). Occasionally an impactor may have a power source of its own. Hayabusa 2, e.g., featured an explosively formed projectile (see Fig. 4), the Small Carry-On Impactor (Saiki et al. 2017), where in April 2019 a charge directed successfully a slug of molten metal at a target to expose subsurface material at the asteroid Ryugu. Attention is usually paid to impactor composition (e.g., pure copper as in Deep Impact) to minimize any unknown contributions to the target material.

The fundamental distinction between an impactor and a hard lander or penetrator is that an impactor performs no functions after impact and so there is no requirement to design its systems to survive.

A penetrator, in contrast (see also the review by Lorenz (2011)) is a landed vehicle that dissipates an appreciable amount of kinetic energy on arrival into the surface material, rather than absorbing the energy with onboard elements such as airbags or shock absorbers. In practical terms, this approach can be used for arrival velocities of between about 10 and 
Fig. 4 The Hayabusa-2 Small Carry-on Impactor: A slightly concave copper disk at right, with a conical explosive charge behind it, forms a high-velocity slug of metal to excavate a crater, Photo: R. Lorenz

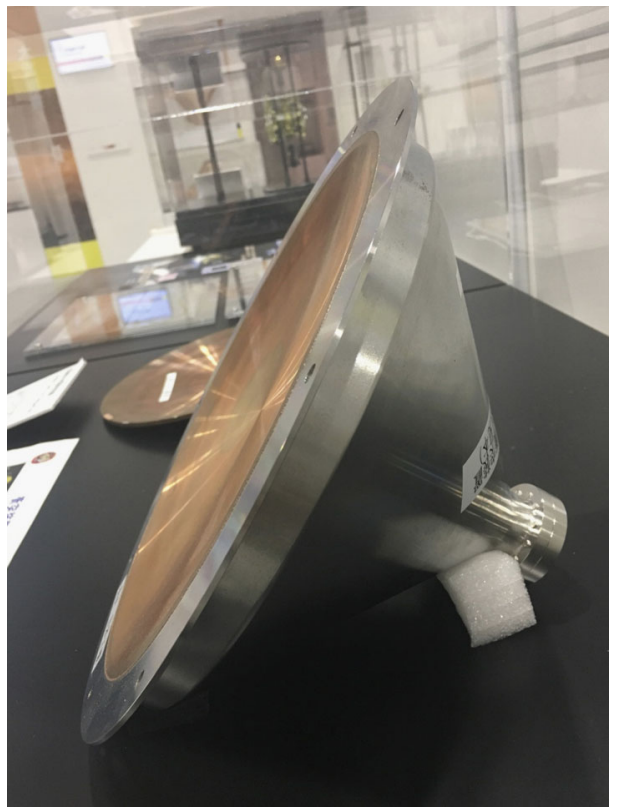

$300 \mathrm{~m} / \mathrm{s}$. At velocities below $10 \mathrm{~m} / \mathrm{s}$ (vehicle mass is also a consideration), the mass saving associated with using terrain for deceleration is not worth the additional risk. Above $300 \mathrm{~m} / \mathrm{s}$ the impact energy becomes too high for scientific instrumentation and other systems to be adequately hardened against the violent deceleration necessary. The impact velocity $V$, penetration depth $d$ and average deceleration $a$ are simply related by $V^{2}=2 a d$. The peak accelerations encountered may be a factor of a few larger than the average value. Impact at $300 \mathrm{~m} / \mathrm{s}$, with deceleration over $2 \mathrm{~m}$, entails an average deceleration of about $2000 \mathrm{~g}$. The vehicle diameter is chosen to achieve the desired penetration characteristics given the assumed (but often highly uncertain) mechanical properties of the surface.

The scientific virtues of a penetrator are that it can directly access subsurface material, getting below the surface layer that may be radiation-processed (in the case of Europa, for example), and that the penetration event itself can be used to perform sample acquisition, e.g. via a side-scraper or nose aperture. Improved seismic coupling, or more importantly, reduced thermally-induced background noise, is another advantage. Penetrators have been proposed to attempt to measure subsurface heat flow, although this is very challenging. While operation at depth in the regolith can introduce operational aspects that are favorable (e.g., reduced thermal cycling, which is important at the Moon), there are potentially unfavorable factors such as uncertainties in radio propagation.

Successful penetration and the avoidance of destructive side loads relies on the vehicle having essentially zero angle of attack (i.e. vehicle axis and velocity vector aligned) and zero incidence (i.e. velocity aligned with the surface normal) to within $\leq 10^{\circ}$ at impact. From an orbit around Europa or Enceladus, a precise and powerful attitude control system is needed to precess the vehicle from a horizontal attitude (typically needed to null the orbital velocity, which is, e.g., $1.389 \mathrm{~km} / \mathrm{s}$ in a circular 100-km orbit around Europa and $0.143 \mathrm{~km} / \mathrm{s}$ in a circular $100-\mathrm{km}$ orbit around Enceladus) to a near vertical orientation at impact, in a freefall time that may be at most a few tens of seconds. This required agility means the perceived cost saving in not requiring propulsion to remove the last $100-300 \mathrm{~m} / \mathrm{s}$ of arrival speed may 


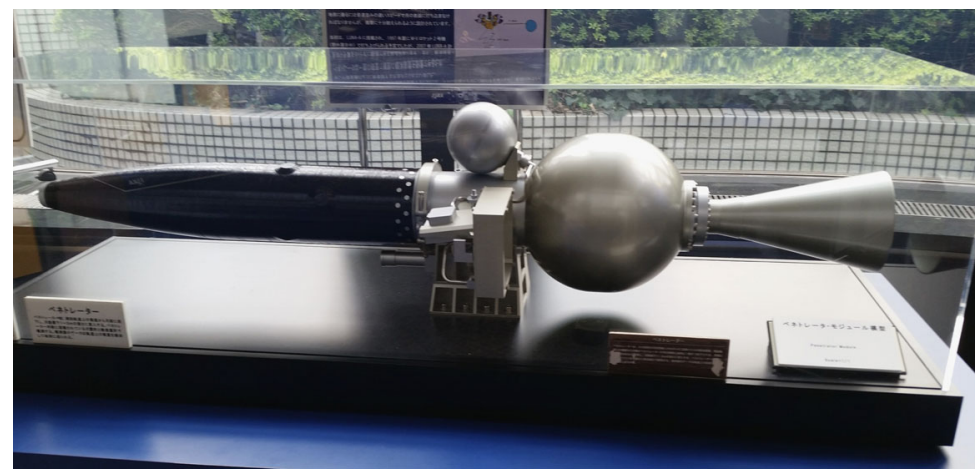

Fig. 5 Model of one of the Lunar-A penetrators, never flown. Only the black element at left would penetrate into the regolith to perform seismic and heatflow studies: the formidable propulsion and attitude control hardware necessary to orient and decelerate the vehicle to survivable impact speed is evident at right, Photo: R. Lorenz

Fig. 6 Model of the penetrator for the ill-fated Mars-96 mission at the Lavochkin Museum in Moscow. An inflatable decelerator is deployed from the aft skirt to retard and stabilize the vehicle during entry, Photo: $\mathrm{R}$. Lorenz

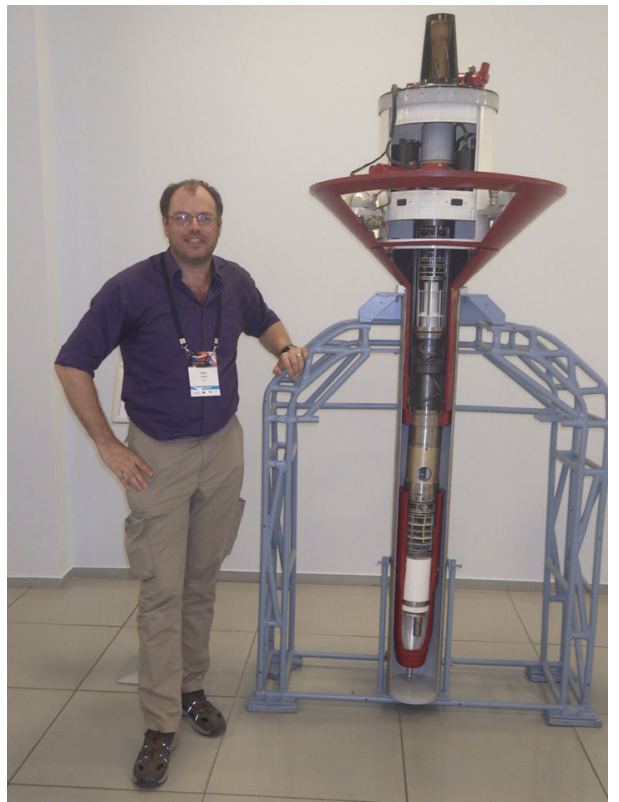

be partly illusory. Penetrators make the most sense in large numbers, such that the loss of one or two vehicles still permits the mission to be accomplished: the non-robustness of even a two-penetrator mission was seen as a weakness of the Japanese LUNAR-A mission prior to its cancellation (see Fig. 5) (Shiraishi et al. 2008).

To date, only two penetrator missions have been launched (Lorenz 2011), the Russian Mars 96 mission with two $\approx 100 \mathrm{~kg}$ penetrators (see Fig. 6, lost at launch), and NASA's two $\approx 4 \mathrm{~kg}$ New Millennium DS-2 Mars microprobes (presumed lost on Mars arrival). The LUNAR-A mission (with two $\approx 12 \mathrm{~kg}$ penetrators) was essentially ready for launch but was cancelled for other factors. Some enthusiasm for penetrators at Europa has been voiced (Gowen et al. 2011) but the fundamental challenges outlined above remain. 
Plumes generated by impactors can be analyzed with the same instruments as those for natural plumes in the previous section. The analytic instrumentation options for a penetrator would have the same goals and geometric constraints as those on an ice-penetrating probe (see Sect. 5.1.2) but have the added challenge of requiring shock tolerance, given that impact loads may be thousands to tens of thousands of g. Inertial scaling is such that miniaturization tends to improve shock tolerance (one can drop a cellphone on the floor and have it still function, but not a TV) but the impact tolerance does impose a substantial qualification burden on the developer.

Particular payload features for penetrators are the opportunity to evaluate the mechanical properties of the target by recording the deceleration at impact, and the use of the kinetic energy of impact to perform sample acquisition (e.g. the penetrator on the proposed CRAF comet mission had a "hook" scraper that ingested a sample at impact, and other concepts for a hollow sampling penetrator have been demonstrated by Lorenz et al. (2003)). On the other hand, the DS-2 mission developed a shock-tolerant sampler that drilled sideways from the penetrator body after impact.

\subsection{Landing Site Evaluation and Selection}

As for any other planetary mission, there are two overarching criteria for the evaluation and selection of a landing site, its scientific potential and the risk it imposes for the lander. For ice-penetrating missions, the thickness and composition of the ice shell are also critical when considering landing sites, as the ice properties will directly affect the performance and efficiency of any ice-penetrating probe, drilling or melting. An ice-penetrating radar, like the one that is flown on the Europa Clipper mission (Phillips and Pappalardo 2014), will be able to infer the ice properties as well as the ice thickness and its lateral variations, and thus to identify potential landing sites.

Synchronously locked moons in eccentric orbits are subjected to tides from their host planet and, to a lesser degree, from their neighboring moons. The energy produced by viscous friction within a body that is periodically stressed by tides is not dissipated homogeneously (Beuthe 2013). Since the viscosity highly depends on the temperature, it is critical to consider that the ice shell is (at least) composed of two layers: an upper cold brittle ice layer and a lower warm ductile layer. The rheological boundary between both layers is in the most simple case manifested by a viscosity change of about $10^{6}$ to $10^{8} \mathrm{Pas}$ in order of magnitude (Kamata and Nimmo 2017), values that are well constrained by laboratory studies. The moon's internal structure and composition affect the spatial distribution of tidal heating, which in turn modifies the interior of the ice shell (e.g. its radial and lateral layering) (Beuthe 2013, 2015). The knowledge of the lateral layering of the upper brittle layer, its composition and its temperature are essential since they would affect both the performance and the efficiency of any ice-penetrating probe, as well as the time required to reach the ice-ocean interface.

Other critical factors for landing site selection are the mechanical surface properties (e.g. ice hardness, porosity, slipperiness), the local surface topography on a lander scale (i.e. $<5-20 \mathrm{~m}$ ), larger surface features such as craters or crevasses, or the solid angle of sky visibility since communication with an orbiter would be mandatory for sending back the data.

Ivanov et al. (2011) discusses the selection of a landing site on Europa, but scientists do not know the most scientifically promising sites at which to land yet. Europa's surface needs to be scouted out first (Phillips and Pappalardo 2014). 


\subsection{Ice-Penetrating Probes}

To reach the subsurface ocean of an icy moon, a probe would need to penetrate the ice while moving the melted or excavated material behind it. This operation can be achieved via three methods: thermal (melting), mechanical (cutting), or hybrid. While thermal systems include any approach that melts ice (e.g. direct melting using a hot point, closed cycle hot water drills, and even direct lasers), mechanical systems use a cutter (drill bit, saw) to break the formation. These approaches, which have been applied in Antarctica and Greenland and are studied for future planetary missions (Bar-Cohen and Zacny 2009; Zacny et al. 2013, 2016), will be described in this section.

\subsubsection{Ice-Melting Probes}

The typical shape of an ice-melting probe (sometimes also called ice-melt probe or melt probe) is that of a cylinder with length $L$ and diameter $D=2 R$. In a simple energy balance approximation that neglects all losses, the heat needed to progress a distance $\ell$ in compact ice via melting is

$$
Q=A \ell \rho\left(c_{p} \Delta T+\Delta H\right)
$$

where $A=\pi R^{2}$ is the probe's cross-section, $\rho$ is the ice density, and $c_{p}$ is the specific heat capacity of ice. Above the triple point, the phase change of the ice is from solid to liquid (melting) and the phase change enthalpy $\Delta H$ (i.e. the specific energy (in $\mathrm{kJ} / \mathrm{kg}$ ) needed for the phase change, also termed latent heat) is the enthalpy of fusion, $\Delta H_{f}=334 \mathrm{~kJ} / \mathrm{kg}$ for $\mathrm{H}_{2} \mathrm{O}$ at $0{ }^{\circ} \mathrm{C}$. Below the triple point, the phase change of the ice is from solid to gaseous (sublimation) and $\Delta H$ is the enthalpy of sublimation, $\Delta H_{s}=2836 \mathrm{~kJ} / \mathrm{kg}$ for $\mathrm{H}_{2} \mathrm{O}$ at $0{ }^{\circ} \mathrm{C}$, which is more than 8 times larger than $\Delta H_{f} . \Delta T=T_{p c}-T$ is the difference between the phase change temperature $T_{p c}$ of ice and the local ice temperature $T$ (the phase change temperature is the melting temperature, $T_{m}$, or the sublimation temperature, $T_{s}$, respectively). Because the triple point of $\mathrm{H}_{2} \mathrm{O}$ is at a temperature of $273.16 \mathrm{~K}\left(0.01{ }^{\circ} \mathrm{C}\right)$ and a pressure of 6.1173 mbar, the operating mode of ice-melting probes under vacuum conditions is sublimation, unless the closing of the hole (by refreezing or covering) raises the pressure in the hole above the triple point pressure, which happens quite rapidly, as observed by Treffer et al. (2006). Therefore, we consider here only melting. If the heating power is $P$, then the penetration velocity $v$ for melting is

$$
v=\frac{P \ell}{Q}=\frac{P}{A \rho\left(c_{p} \Delta T+\Delta H\right)}
$$

Note that the penetration velocity scales inversely with the probe's cross-sectional area and is independent of the probe's length. This is why the typical design is a tube with a large aspect ratio, being limited by the volume required for subsystem, payload and tether integration. Note also that $\rho$ and especially $c_{p}$ are temperature dependent. For low temperatures, one has to use averages over the temperature range $\left[T, T_{m}\right]$. Also, $T_{m}$ depends (weakly) on ambient pressure and on salinity (freezing point depression). Because Eq. (2) does not consider losses, it gives only a rough estimate of the penetration velocity, in fact, it relates the minimum power requirement $P_{0}$ to a given penetration velocity $v$ via

$$
P_{0}=A \rho\left(c_{p} \Delta T+\Delta H\right) v
$$

In fact, insufficient heat causes the probe to freeze in and excessive heat produces an oversized hole and wastes power by raising the meltwater temperature far above $T_{m}$. To obtain a 
Fig. 7 Required heating power $P$ as a function of penetration velocity $v$, without (solid lines) and with conductive losses (broken lines)

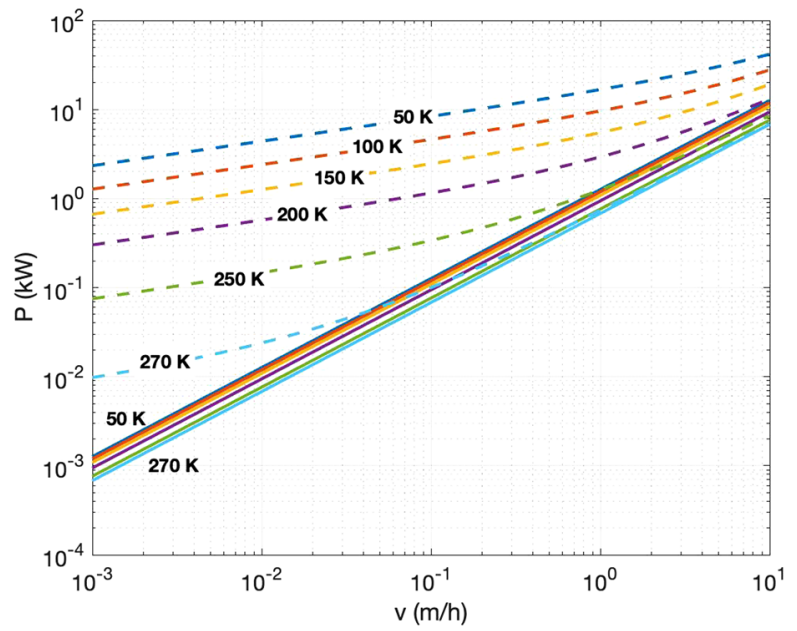

more accurate result, losses need to be considered, most importantly the losses due to lateral heat conduction into the ice. The lateral conduction losses have been estimated by Aamot (1967) for a cylindrical probe with the constraint that the melt water stays liquid all around the probe's hull. According to Ulamec et al. (2007), the resulting equation for the lateral conduction losses $P_{l c}$ can be approximated by

$$
P_{l c}=932 \mathrm{~W} \mathrm{~s} / \mathrm{Km}^{3} \cdot x^{0.726} \cdot R^{2} \Delta T v
$$

where $x$ is the numerical value for $L /\left(v R^{2}\right)$, being made dimensionless by multiplying it with $1 \mathrm{~m}^{2} / \mathrm{s}$. Hence, the total power required by the probe to penetrate the ice with a velocity $v$ is given by

$$
P=P_{0}(A, v, T)+P_{l c}(A, L, v, T)
$$

Figure 7 shows the required heating power of a typical ice-melting probe $(L=1 \mathrm{~m}, D=$ $10 \mathrm{~cm}$ ) as a function of penetration velocity. The solid lines show the minimum power requirement according to Eq. (3), while the broken lines depict the total power including losses according to Eq. (5). Applying such a melting probe with a heating power of $10 \mathrm{~kW}$ would allow a melting velocity of about $1 \mathrm{~m} / \mathrm{h}$ in Europan ice. Consequently, it would take over a year (and an energy of $>100 \mathrm{MWh}$ ) to reach the ice-ocean interface in a depth of ca. $10 \mathrm{~km}$. Lowering the heating power to $5 \mathrm{~kW}$ would reduce the melting velocity to about $0.1 \mathrm{~m} / \mathrm{h}$ and increase the required energy to $>500 \mathrm{MWh}$, while taking more than 10 years, because much more energy is lost by conduction into the surround ice, just to warm it up. Therefore, low-power melting is disadvantageous. Figure 8 shows the efficiency $E=P / P_{0}$ as a function of penetration velocity. It can be seen that $E$ becomes very small for penetration velocities $<1 \mathrm{~m} / \mathrm{h}$ and cold ice. For example, in 100-K Europan ice, the efficiency at this penetration velocity is below $10 \%$. All other losses are neglected here because they are small as compared to the lateral conduction losses. The interested reader is referred to Ulamec et al. (2007) and Dachwald et al. (2013).

The application of ice-melting probes for subsurface ice exploration is not a new idea. It can be traced back to the beginning of the 1960s, when Philberth (1962) designed an instrumented ice-melting probe for measuring temperatures inside a glacial ice sheet in Greenland. In the following decades, terrestrial ice-melting probes were also developed at AWI, the Alfred Wegener Institute for Polar and Marine Research (SUSI, Tüg and Damm (2003)), at 
Fig. 8 Efficiency $E=P / P_{0}$ as a function of penetration velocity $v$

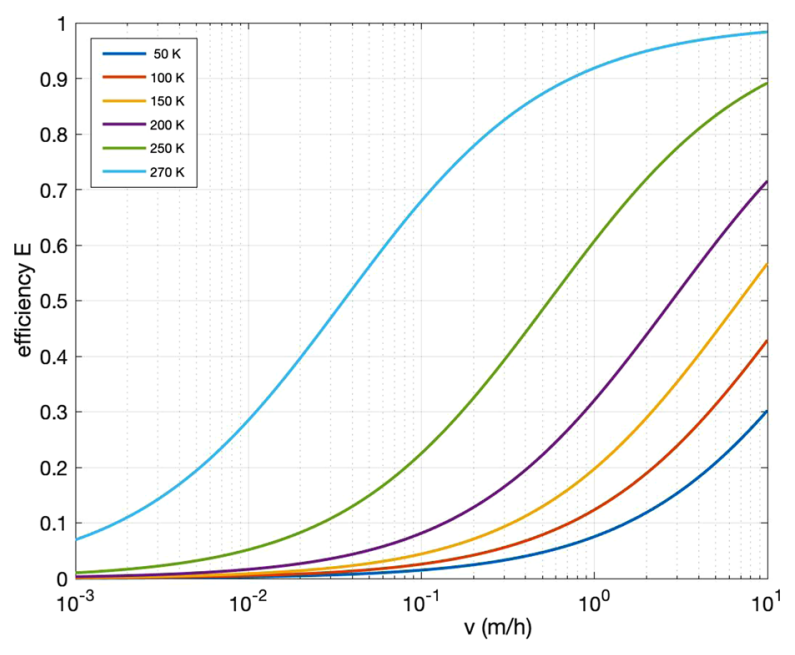

DLR, the German Aerospace Center (Ulamec et al. 2005), at NASA/JPL (Cryobot, Zimmerman et al. (2001a,b)), at the Austrian Institut für Weltraumforschung (IWF) in Graz (Treffer et al. 2006; Kömle et al. 2018b,a), at the Chinese University of Jilin (RECAS, Talalay et al. (2014)), at the University of Washington's Applied Physics Laboratory (Ice Diver, Winebrenner et al. (2013)), at Stone Aerospace (VALKYRIE, Stone et al. (2018a)), and at the German FH Aachen University of Applied Sciences (IceMole, Dachwald et al. (2014)).

The IceMole is currently the only ice-melting probe that is able to navigate in the ice. Traditional ice-melting probes have three main drawbacks: 1) they penetrate only vertically downwards and it is difficult to (intentionally) change direction; 2) they cannot penetrate layers with a high content of silicates; 3 ) they cannot be recovered from greater depths. To remedy these drawbacks, the IceMole design was developed at FH Aachen University of Applied Sciences. The IceMole design is based on the novel concept of combined melting and drilling (or - more precisely - screwing) with a hollow ice screw at the tip (see Fig. 9). The probe has the shape of a rectangular tube $(15 \mathrm{~cm} \times 15 \mathrm{~cm}$ cross section $)$ with a $\approx 3-\mathrm{kW}$ melting head. The quadratic cross section is required to counter the torque of the ice screw. The required electric power is generated by a surface aggregate and transmitted via a cable that may be uncoiled from the probe. The power cable may also be used for communications and data transfer to the surface. The driving force of the ice screw presses the melting head firmly against the ice, thus leading to a good conductive heat transfer. The ice screw is also able to drag the probe through moderately thick layers with high silicate content. It can, however, probably not cope with obstacles that are larger than the diameter of the screw. The ice screw can also be used for the clean sampling of liquids into the IceMole for in-situ analysis. The IceMole can change direction by differential heating of the melting head, which generates a torque that forces the IceMole into a curve. Therefore, it can also melt upwards, against gravity, to be recovered from the ice. The current design of the IceMole is adapted to the subsurface investigation of terrestrial glaciers and ice shields, but in the long run, the probe should also be adapted to extraterrestrial ice research. An IceMole with advanced navigation capabilities was build for the DLR-funded Enceladus Explorer (EnEx) project (Konstantinidis et al. 2014). After tests on alpine glaciers, this EnEx-IceMole (Dachwald et al. 2014; Kowalski et al. 2016)) was used for the successful clean sampling of brine from an englacial reservoir at Blood Falls, Antarctica (Lyons et al. 2019; Campen et al. 2019), 

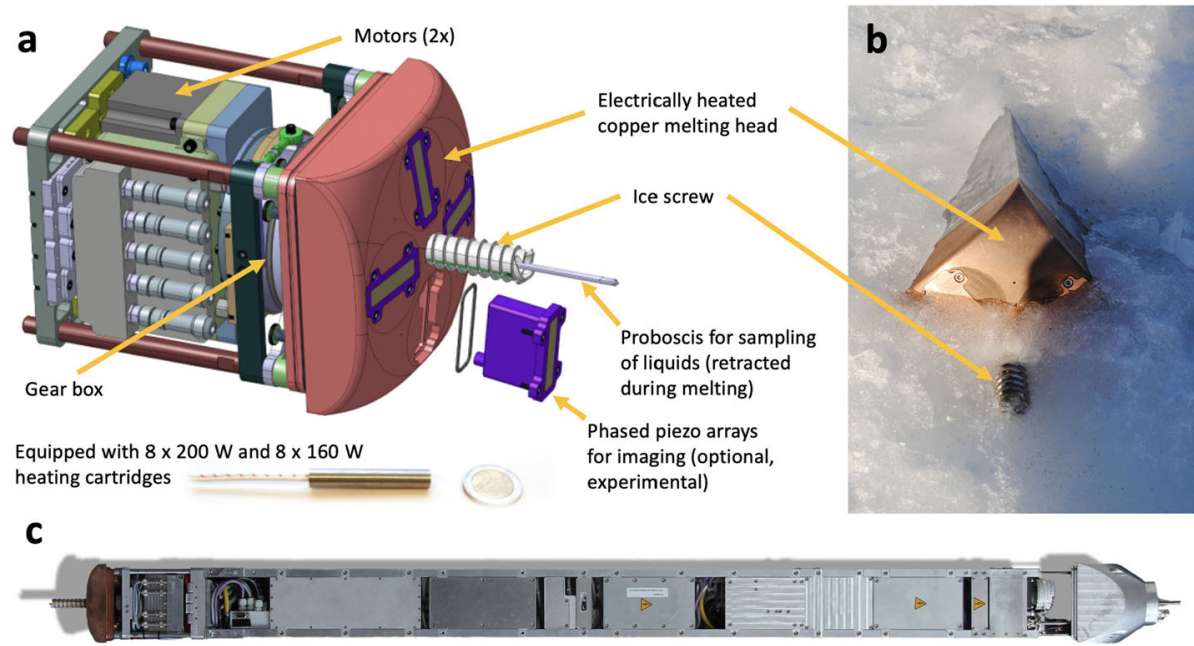

Fig. 9 EnEx-IceMole: (a) CAD drawing of the melting head. (b) Return to the surface of Canada Glacier, Antarctica. (c) The full 2-m long probe with the hull removed. Credits: FH Aachen

however after melting through much less ice (only ca. $17 \mathrm{~m}$, see German et al. (2019b)) than it would be required on an icy moon.

\subsubsection{Ice-Drilling Probes}

As it became evident in the previous section, ice-melting probes suffer from the problem that they are not very efficient, especially in low-power operations, where most of the power is wasted to heat up the surrounding ice. A mechanical approach can be two orders of magnitude more efficient than a thermal approach (see Fig. 10), but it has its own disadvantages related to the transport of chips. Thermal ice-melting probes produce liquid that refreezes behind them. Mechanical drills, however, require either removing the cuttings from the hole or transporting them behind the probe and compacting them against the top of the borehole. Transporting cuttings to the surface requires a stable borehole (the ice on Europa shifts on a daily basis) and transporting and recompacting chips is a complex task that requires a compactor to generate a pressure of $30 \mathrm{MPa}$. Figure 10 shows the comparison of three penetration approaches in $240 \mathrm{~K}$ ice using the same bit with integrated heater. From the penetration and power standpoint, the ice-melting probe was slowest and required the most power, while mechanical drilling was the fastest and required the least power (mechanical drill energy did not include the energy of transporting chips). Importantly, a slushing approach also had higher performance than pure melting (penetration was about one order of magnitude faster).

\subsubsection{Hybrid Probes}

In summary, mechanical systems break the icy material efficiently, but transport ice chips inefficiently. Thermal systems have an effective chip removal approach, but a power intensive ice-melting step. The Search for Life Using Submersible Heated (SLUSH) drill is a hybrid, thermomechanical ice-drilling probe system that combines the most efficient aspects of these two techniques (Zacny et al. 2018). SLUSH is a 5-m long, 50-cm diameter probe 


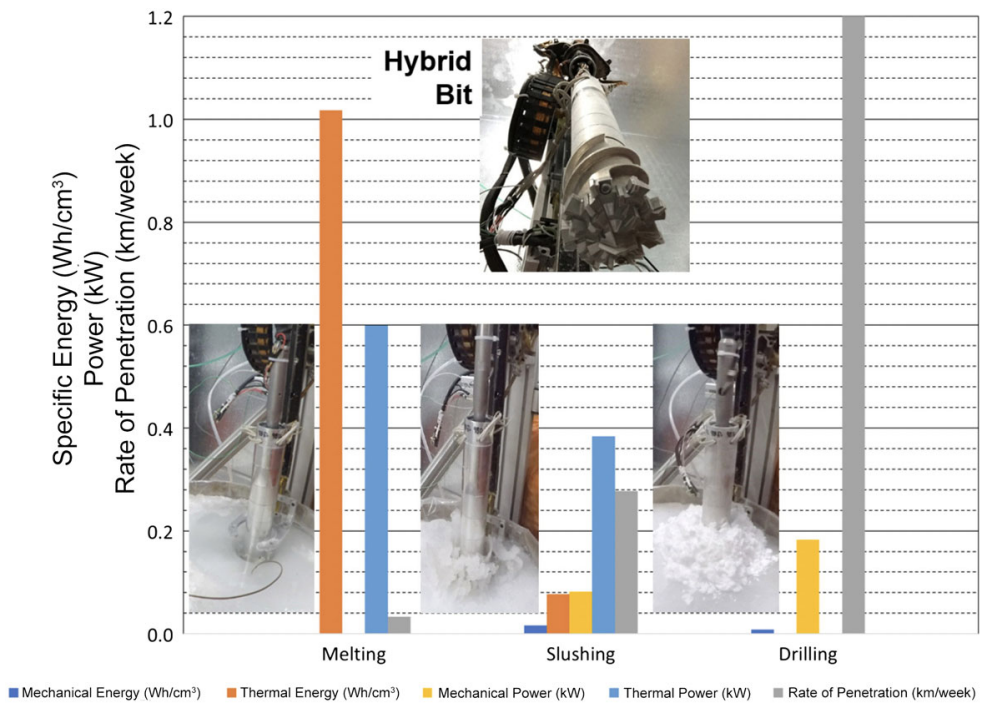

Fig. 10 Comparison of melting, slushing, and drilling (without transport of chips), Credits: Honeybee Robotics

Fig. 11 Conceptual design of SLUSH, Credits: Honeybee Robotics
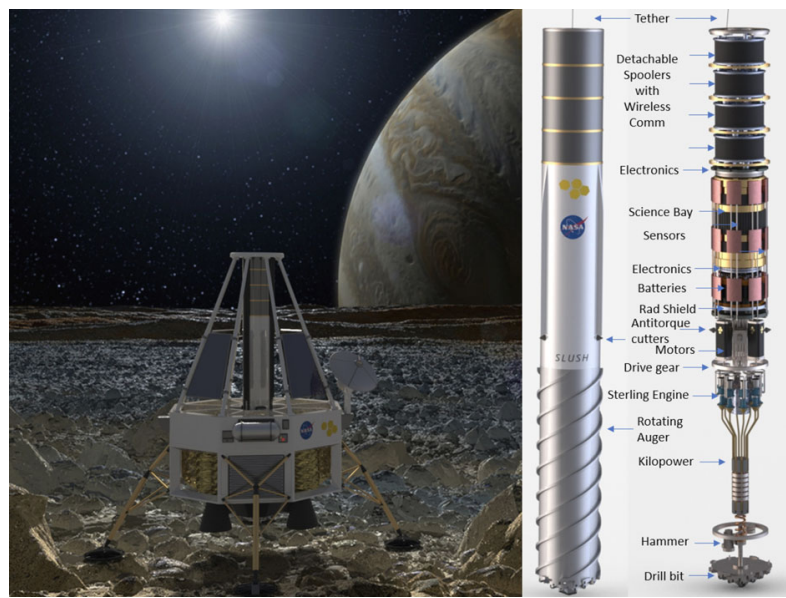

with a heated drill bit in front, anti-torque cutters on the side, and several tether bays on top (see Fig. 11). The probe is partially flooded - only critical subsystems are inside a pressure vessel; this allows the probe to sink rather than float. SLUSH utilizes a mechanical drill to break the formation, and partially melts the fragments to enable the efficient transport of material behind the probe. The resulting slush behaves like a liquid despite being partially frozen, enabling a significant reduction of the power required for melting the full volume of ice. Further, because a mechanical approach generates higher penetration rates for the same power, SLUSH can reach the ocean in a much shorter time than a pure ice-melting probe. Once SLUSH passes through the hazardous cryogenic ice, it could use a purely thermal approach to melt through the warmer ice without the need for mechanical cutting. SLUSH incorporates the Kilopower reactor for both thermal and electrical needs. The fission reactor 
can be turned on and off and is self-moderating, significantly simplifying thermal management. The probe is physically connected to a surface station by a communications tether, housed in several spool bays that are left behind in the ice once the spool is depleted. This allows each tether section to be purpose-designed. For example, the top section, which may see $150 \mathrm{kPa}$ shear stresses on a diurnal cycle, will be reinforced with Kevlar. Leaving the spools behind also shortens the probe length as it descends, making penetration more efficient. While Kevlar reinforcement and the refrozen channel left behind by the probe may provide protection from the diurnal stress environment, if the tether does break, broken sections can be used as "Tunable Tether" for communication.

\subsubsection{Penetration of the Ice-Ocean Interface}

After the ice-penetrating probe has reached the bottom of the ice shell and thus the ocean, the integrated underwater vehicle can be disconnected from the ice-penetrating probe. Since the nature of the ice-ocean interface is unknown, one has to prepare for the worst case. One must expect a lot of porosity and brine channels, as the ice-melting probe approaches the ice-ocean interface, which is expected to change the probe's motion and give an indication that the ice-ocean interface nears. At the "last piece of ice", the motion of the probe must be stopped and an uncontrolled entry into the ocean must be prevented. Therefore, the sensors of the ice-penetrating probe must be able to sense the interface and make a controlled stop before the release of the underwater vehicle (or one has to find a way to make an uncontrolled entry possible). The ice-penetrating probe may be stopped by arresting the tether deployment or by activating a buoyancy mechanism, but the technical details are not trivial and subject to future research and development.

\subsection{Underwater Vehicles}

Exploring the oceans with underwater vehicles had been a topic of technological innovation and development for over 50 years. Major milestones had been the introduction of tether-connected, remotely-operated vehicles that proved to be the backbone of today's underwater operations and the advent of small, powerful acoustic mapping systems that gave autonomous underwater vehicles a regular role in underwater exploration. The experience with these basic robotic tools will provide solid assessment criteria for the design of underwater vehicles that shall be deployed in the oceans of icy moons. However, there are some major differences to terrestrial systems:

- For icy moons, the size and weight constraints for underwater vehicles are very restrictive, which also leads to a very limited availability of power sources.

- For true exploration capabilities on icy moons, underwater vehicles need the capability to adapt to unexpected environments and tasks. This probably requires re-programmability and controllability from Earth, which implies a reliable permanent communication link between the submerged vehicle and the surface station and a frequent link from there to Earth.

- For icy moons, underwater vehicles have to undergo two test categories, underwater and space. This limits the selection of components significantly.

All these general requirements are major technological challenges that have to be evaluated with the aim to decide whether today's technologies can provide a solution for planetary missions. Components cannot be taken from the shelf but will heavily rely on specifically designed modules down to the sensor level. Proven terrestrial underwater vehicles like NereidUI (Bowen et al. 2014), BRUIE (Berisford et al. 2013), DEPTHX (Stone et al. 2018b) and 
Fig. 12 DEPTHX final design, showing ellipsoidal geometry and syntactic floatation panels (from Stone et al. (2018b))

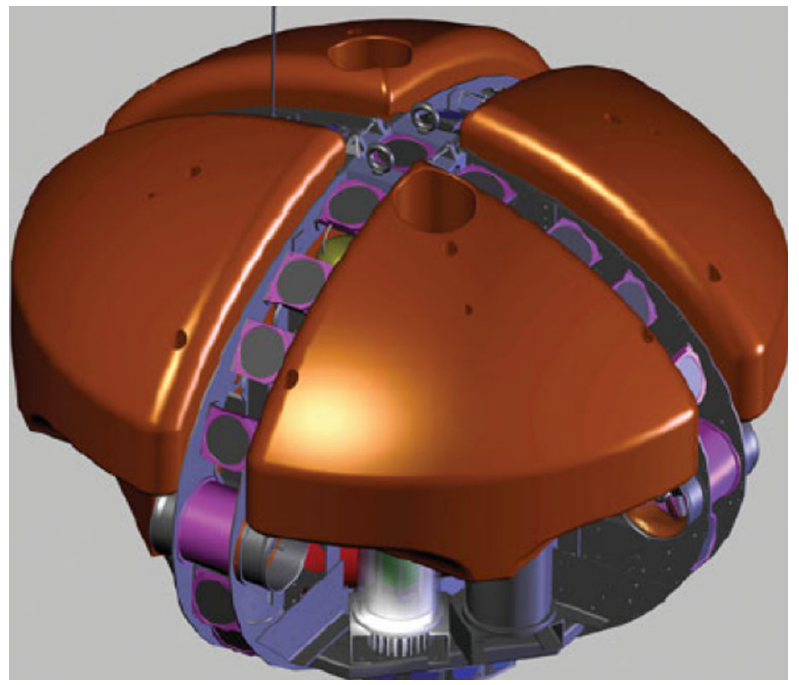

Icefin (Meister et al. 2018) have pioneered under-ice investigations of Polar oceans and provided insight into the technological challenges that autonomous or remotely operated vehicles are facing. At the same time, they assisted in developing a scientific mission scenario for the identification of regions of interest and the tools that are needed for a comprehensive coverage of relevant processes and events. Based on this experience, the next step towards miniaturization of vehicle designs in conjunction with the selection of fit-for-purpose instrumentation can be made. In 2018, DLR has started a new initiative, the TRIPLE-nanoAUV project (TRIPLE stands for Technologies for Rapid Ice Penetration and sub-glacial Lake Exploration and the nanoAUV is planned to be a ultra-miniature autonomous underwater vehicle).

The mobility of underwater vehicles is characterized by near-weightlessness, so that a vehicle can freely float around in three dimensions. One can differentiate between two vehicle classes: vehicles that are free-floating and make use of a recoil-type propulsion system and wheeled vehicles that need to stay in touch with a surface, either the seafloor or, in case of an ice-covered ocean, the bottom of the ice shell. Both have different specific characteristics. While the wheeled systems do not need exact balancing and are already in touch with the surface that is to be explored, they may face major issues on rough surfaces. Under those circumstances, free-floating vehicles can demonstrate their mobility advantage as they can circumvent obstacles. This characteristic is particularly important when miniaturization is a major design goal. While wheeled vehicles need a certain size to deal with obstacles of similar sizes, free-floating systems do not have to follow such a design scheme. The scientific objectives drive the mobility requirements of underwater vehicles. For the sampling of liquids or solids, for example, the vehicle shall have a high maneuverability and, in case of a free-floating system, hovering or "landing" capabilities. An example for the implementation of this specific maneuverability requirement is the DEPHTX vehicle (see Fig. 12). Its spherical design provides hovering and rotation capability. Furthermore, the vehicle is equipped with 6 thrusters for full actuation. The configuration of the thrusters also allows to compensate for a possible failure of an individual thruster (Stone et al. 2018b).

If the mission scenario requires docking of the underwater vehicle to a fixed base station under the ice shell (at the point of penetration), specific mobility requirements are needed. The position of the docking station can be tracked down to a typical accuracy of 2 to $10 \mathrm{~m}$. 
Fig. 13 The ROBEX Glider - a blended wing design for extended operating ranges and long-term deployments (from Waldmann et al. (2016))

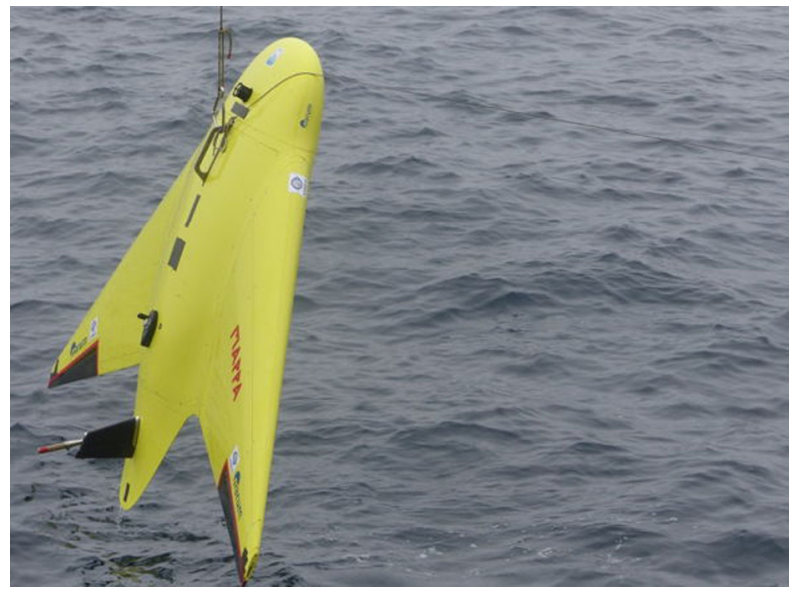

Within that range, the vehicle has to be able to slowly approach and establish a connection to a fixed endpoint. For under-actuated robots, this results in a high requirement on control and thruster performance. As an alternative approach, acoustic and optical modems could be used to transfer the collected scientific data from a more remote location to the base station. These modems have been extensively tested and used in terrestrial underwater environments. Although they have proven to work effectively, situations like high water turbidity may occur for the optical modem or, for the acoustic modem, transient behavior for the acoustic channel, which will lead to a massive loss of transmission capabilities. Therefore, it is worthwhile to consider also docking concepts, with all related pros and cons, to finally decide what concepts work best for which situation in regard to reliability and consistency. More conventional vehicle concepts are making use of torpedo-shaped vehicles that are a good compromise between low drag and flexible extensibility. Low-drag hull shapes have been often considered as well, but the advantages are quickly wiped out if sensors or antennas have to stick out of the outer skin of the hull. A new class of underwater vehicles are glider systems that are particularly useful for long-term missions (with operation times of weeks to months, see Fig. 13). Their buoyancy engines are well matched for energyefficient slow forward motion. A blend of buoyancy engines with thrusters or synthetic jets have been conceived and evaluated as well and for under-ice missions, where the system has to find its way back to the base station, a hybrid propulsion system is indispensable. Energy-efficiency is key to achieving long ranges (up to thousands of kilometers). It comes down to minimizing the velocity, taking into account the basic energy utilization of support systems. Classical underwater glider designs that make use of torpedo shapes do not immediately lend themselves to the idea of keeping the vehicle at a fixed position. However, with the glider design shown in Fig. 13, a blended wing shape, the integration of an airplanelike landing gear appears to be technically feasible. This would allow the glider to stay for weeks to months at a fixed location. All mentioned categories and concepts are also considered for space missions to icy moons. These concepts have to be reconsidered, however, under the premise of a significant size and mass reduction. Current developments go into the direction of smaller hull diameters and extended lengths (Stone et al. 2018b; Lawrence et al. 2018; Wirtz and Hildebrand 2016). Although this approach appears to be attractive for tests in Earth-analogue environments like in Antarctica, one has to keep in mind that space missions require radically miniaturized vehicle designs. 
Based on previous studies by Hand et al. (2017) and ongoing experiments like BIOMEX (de Vera et al. 2019) and the to-be-launched BIOSIGN project (de Vera and the Life Detection Group of BIOMEX/BIOSIGN 2019), the base for narrowing-down the scientific requirements has been set. To keep pace with this ongoing activity, it has to be accompanied by a comparable effort in the design of the carrier system. It appears advisable to select an integrated development approach that takes the scientific payload, power, navigation and communication capabilities and the miniaturization of the vehicle hull into account. The outcome of this exercise will be that criteria can be identified that will indicate what can be achieved with the current available technologies and which milestones have to be passed to make the system ready for an icy moon mission. Planning for such a mission will also have to incorporate the experience from terrestrial exploration and sampling campaigns, e.g. at the subglacial lakes Vostok, Whillans, and Ellsworth (Mowlem et al. 2016).

\section{In-Situ Instrumentation for Analysis of Plumes and Plume Material, Ice, Water, Dust, Organics}

\subsection{Payload}

The main driver for payload selection is the payload's capability to answer the scientific questions related to the habitability of the icy environments and to the search for life. It is clear that different mission scenarios require different payloads. In this section, possible payloads, which also have to be tested for their environmental suitability to be used and operated in space and exo-oceans, are discussed for three different potential mission concepts:

1. A plume-catcher mission

2. A lander / surface station with an ice-penetrating probe

3. An underwater vehicle for ocean exploration

We would like to emphasize that the instruments listed below have to be adapted to the icy moons with their new mission scenarios and new environmental conditions compared to their original missions (e.g., on Mars). This needs to be done in collaboration with ocean experts, and it has to be tested in terrestrial analog ocean systems for finally getting future mission-appropriate sensor payloads.

\subsubsection{Payload for a Plume-Catcher Mission}

While a high-velocity plume sampling scenario with mass spectrometry, as described in Sect. 4.1, does not require the "catching" of plume material, this is absolutely necessary for a slow flyby scenario (e.g. in a wheel collector). In this case, the material would be analyzed with a multi-spectroscopic device, including Raman, IR, UV/VIS, fluorescence and mass spectroscopy. While a mass spectrometer can easily investigate the elemental and isotopic composition of the collected plume particles (Coustenis et al. 2009), it can only give hints about molecular structures. The other spectroscopes, in combination, can deliver more precise information about molecules and molecule groups with relevance for life up to the detection of real cells and even signs of an existing life cycle (Serrano et al. 2014). If the multi-spectroscope is additionally combined with a miniaturized microscope, its information could be combined with the microscopic images and, according to the observed microscopic structures, it may be determined whether the captured particles contain real cells or cell components, as such a detection would prove the existence of life. The combination 
of laser spectroscopy with microscopy is well-established in Confocal Laser Scanning Microscopy (CLSM) research, but, in the coming years, further work is needed to use the full potential of non-destructive confocal laser scanning spectroscopy in combination with confocal laser scanning microscopy. This would not require an extraction step, and the trapped sample could be analyzed within the aerogel and without direct contact between the sample and microscopy hardware. Further details and approaches for combined investigations were also discussed by the Europa Lander Science Definition Team (Hand et al. 2017). There it was argued that multiple approaches are required for the identification of organics and the detection of life, such as the ability to measure elemental abundances, the ability to examine what chemical bonds could be or are present, and the ability to investigate morphology. The spacecraft also needs to be equipped with an UV-IR imaging spectroscope for mapping the physical and chemical surface properties in relation to the surface processes (Coustenis et al. 2009). It could detect organics, volatiles, and physical properties of water ice, as well as a temperature map of cracks (Coustenis et al. 2009). A high-resolution stereo camera $(2-10 \mathrm{~m} / \mathrm{pixel})$ would be good to image plumes at different time scales, phases, and distances.

\subsubsection{Payload for a Lander with an Ice-Penetrating Probe}

An ice-penetrating probe for a lander mission to Enceladus or Europa (Dachwald et al. 2013, 2014; Kowalski et al. 2016; Zacny et al. 2018) could be equipped with a variety of instruments. The lander or surface station itself could serve mainly as a data storage and to relay the data to an orbiter and further on to Earth (Zacny et al. 2013). The ice-penetrating probe itself could investigate the habitability of the ice and could be equipped with temperature sensors able to measure temperatures on the surface and inside the probe (Zacny et al. 2013). Besides getting knowledge on the ice temperature, it would be important to get information about the pressure, the potential content of liquid water within the ice, the humidity of potentially existing ice caves or cavities above potential water pockets within the ice, the salinity and the $\mathrm{pH}$ of the water bodies, and the gas composition which could be gained during the operations performed within the ice. To get this data, it is absolutely necessary that sensors which are able to detect the $\mathrm{pH}$, humidity, salinity, and gas-composition are part of the instrumentation of the ice-penetrating probe. The latter could be measured by mass spectrometers, although it would be challenging to integrate it into the ice-penetrating probe because of its mass. Therefore, it must be seriously evaluated whether this kind of instrument could be miniaturized to the required degree. A camera with both macro- and microscopic lenses would allow observations through a window in the sidewall about the ice, inclusions and potential traces of life. This window could also allow to analyze the molecular content of the ice and the inclusions by miniaturized Raman and IR spectroscopes (Böttger et al. 2017; Genceli et al. 2009; Moore and Hudson 2000; Dalton et al. 2003). For an IceMolelike ice-melting probe, it could also be possible to use melt-water or an ice core transferred into the melting probe for direct analysis of the melt-water or the ice core inside the probe by spectrometers and labs-on-a-chip or microarrays and biochips for life detection (Parro et al. 2011).

\subsubsection{Payload for an Underwater Vehicle}

An underwater vehicle for ocean exploration would not be independent from the lander and the ice-penetrating probe scenario, because it must be contained in the ice-penetrating probe until it reaches the ocean to be deployed. For the study of these oceans, the underwater 


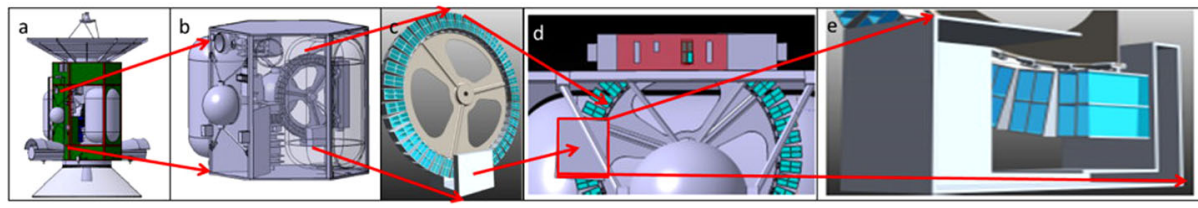

Fig. 14 Details of a potential plume-catcher payload: (a) Orbiter with payload arrangement. (b) Segment with aerogel-sample collector-wheel. (c) Detail of sample collector and collector window. (d) Detail of sample wheel and analytical (red) box. (e) Detail of the analyzer box: samples are passing through the spectrometer laser within the box (from a student study at FH Aachen, 2016)

vehicle also needs to investigate the habitability of the ocean and to search for potential life forms and biomarkers as evidence for life. The required payloads for this vehicle are sensors to measure temperature, $\mathrm{pH}$, salinity and gas (Tengberg et al. 2006) as well as their gradients, and also labs-on-a-chip for the analysis of chemical ocean composition (Tengberg et al. 2006; Yücel et al. 2015) and biochips and microarrays (Parro et al. 2011) able to detect traces of life. Further investigations on such kinds of sensors for their suitability and adaptability to the exo-ocean environments should be a major topic for international and interdisciplinary research and investment in the coming decade. Miniaturized spectrometers such as Raman could also be integrated into such a system. Because the space on such a mobile submarine is very limited, instruments such as multi-spectrometers or mass spectrometers would better be operated on the ice-penetrating probe itself or on the lander. But if the surface station also has to analyze samples from the ocean, this needs a sample return operation of the probe together with (part of) the underwater vehicle, which could carry the ocean sample. This means a complex operational scenario to the surface, where a lab has to be installed on the surface station for further analysis. This option could complicate the entire mission procedure and could by very risky and will certainly not be part of the first generation of probes to be sent to the icy worlds within our solar system.

\subsection{Payload Arrangement and Operational Sequence}

The arrangements of the payloads within the spacecraft or the probe depend on the sampling procedure and on the subsequent analysis of the samples by non-destructive analytical methods and by destructive methods. Mass spectroscopy and laser-induced breakdown spectroscopy (LIBS) are destructive methods, which need either extra samples or which have to be done after all non-destructive analytical methods have finished. Of course, the handling of samples and the operational sequence for analyzing them is also mission-dependent. In the following, the three above-mentioned mission scenarios are taken into consideration.

\subsubsection{Sampling, Sample Handling, and Operational Sequence for a Plume-Catcher Mission}

On a plume-catcher mission, sampling will be done during multiple plume-flythroughs, using, e.g., an aerogel sample-collector wheel, as it is shown in Fig. 14. The wheel will transport the material trapped in the aerogel to the different instruments within the spacecraft for subsequent analysis. At the beginning, the experiments with non-destructive methods have to be done, i.e., the microscopic identification of trapped samples and their analysis with laser excitation and the multi-spectrometer. Only afterwards, instruments such as LIBS and mass spectrometers can analyze the elemental and isotopic composition of the samples. In parallel, during the flybys, the UV-IR imaging spectrometer will map the physical and chemical surface properties and the stereo camera will observe plume activity. 


\subsubsection{Sampling and Sample Handling on an Ice-Penetrating Probe}

After the lander has deployed the ice-melting probe to the surface, it first sublimates and then melts into the ice. After having reached a certain depth, it can start to measure ice temperature, $\mathrm{pH}$ and salinity with dedicated sensors. Then, at a depth of a few meters, ice and melt-water can be sampled. Melt-water can be sampled with orifices at the tip of the probe. One method to sample ice is an ice-screw at the tip of the probe, like in the IceMoleconcept (Dachwald et al. 2013, 2014). Given the forward motion of the probe, an ice core will be (passively) transported through a transparent tube into the probe for in-situ analysis (and later exit the probe at the rear). The in-situ analysis methods could include Raman- or IR-spectroscopes to determine the presence or absence of dust inclusions, organics, and potential life forms. The melted ice core at the back of the probe could then be used for analysis through a lab-on-chip, microarrays and biochips (Parro et al. 2011). This method, however, should only be started when the spectrometers have found clear evidence for the presence of bio-relevant material within the sample. Through a transparent window in the probe, the same spectrometers and even macroscopic and microscopic cameras could analyze the ice wall that is almost in contact with the sidewalls of the probe. Of course, all instrumentation in the probe is limited by the internal volume of the probe.

\subsubsection{Sampling and Sample Handling Operations on an Underwater Vehicle}

After the release of the underwater vehicle into the ocean, sensors in direct contact with the ocean water would measure temperature, $\mathrm{pH}$, salinity and dissolved material. A camera with a bright light source could operate in this dark environment, to check which areas could be promising for sampling, but the illuminated volume will be very limited, as it is for terrestrial deep-sea exploration. Much more challenging will be the sampling procedure itself. A fluid sample management system is required, which allows to pump water with interesting material into the underwater vehicle. This system could be implemented with micrometerdiameter tubes, which transfer the sampled liquids separately to the labs-on-a-chip for the chemical and physical analysis and to the biochips and microarrays, where further biochemical analysis could be done. Another already existing sampling system could be promising for use on an icy-moon underwater vehicle: a filter system that is included in a sampleprocessing chamber for the extraction of material that could be analyzed microscopically. In Earth's oceans, life is either floating or bound to particulate material. Therefore, such a filter sampling device would be well-suited for being mounted on an underwater vehicle, especially because of its heritage from current in-situ research in terrestrial oceans (Breier et al. 2014). Using micrometer-sized probes for sampling, samples can be accurately related to their camera-selected sampling location, but there is the risk of missing potentially existing life forms in the vicinity of the sample location. In contrast to that, sampling with a filter system can accumulate material from a larger volume, including the surroundings of the selected sampling location. In this case, however, the relation to the exact sampling location is less accurate. Because the latter sampling method increases the probability of collecting life or traces of it, this may be favorably used, although the environmental context would be lost to some extent.

\section{Enabling Technologies}

Exo-ocean exploration missions require some general key technologies that do not depend on the exact mission objective and design. Penetrating the surface of an icy moon requires 
an immense amount of energy. But already lander missions suffer from the scarcity of solar power in the outer solar system. When a probe is in the ice or the ocean, data must be sent back to the surface station (from where they are relayed to Earth) to be able to control the probe (as long as it is not $100 \%$ autonomous) and to get data back (even if it is $100 \%$ autonomous). Communicating through dozens of kilometers of ocean and ice is a considerable problem. Another problem is navigation in the ice and the ocean, given that external references like stars are not available but only the absolute position and orientation of the surface station. At least on Europa, the radiation at the surface from the high-energy particles trapped in Jupiter's strong magnetic field is immense and requires intense shielding for the electronic components. As well, it renders solar power systems infeasible so that a nuclear power source is required. This source, as well as the hardware that penetrates the surface, requires particular methods for cleaning and sterilization so that the moon is not contaminated by terrestrial life and the planetary protection requirements are fulfilled. Since the $\Delta V$ to land on an icy moon is very large, every landed kilogram requires probably dozens or even hundreds of kilograms in Earth orbit at departure. This makes miniaturization especially important. Another key technology is autonomy, where relevant work has already been done in Earth's oceans for at least 15 years (German et al. 2008) and also for exo-ocean-related research (Aguzzi et al. 2020; Arora et al. 2019). This, however, is a wide field that would go beyond the scope of this chapter. Also, in contrast to the other mentioned key technologies, there is a huge terrestrial market for autonomous systems and space applications will be able to profit from them.

\subsection{Power}

One of the major challenges of any space mission, including landers and probes that operate on or underneath the surface of moons in the outer solar system is the provision and distribution of power. While orbiters like Rosetta (Fiebrich et al. 2004) have demonstrated to work with solar power at Jupiter distance from the Sun, this is more difficult for a surface station, as size and means of orientation towards the Sun are limited. For solar cells at Europa, the high radiation flux at the surface (see 6.4) would also lead to a very rapid degradation. Ice-melting probes are facing the additional difficulties of a very high power demand (see the analysis of efficiency and minimum power required in Sect. 4.4.1) as well as the need to make the power available at the tip of the probe, typically far below the surface.

As power sources, solar generators, radioisotope thermal generators (RTGs) or fission reactors are to be considered. The solar radiation flux at Europa is less than $4 \%$ of the value at Earth and only about $1 \%$ at Enceladus. Although orbiters with large solar arrays are feasible (e.g. JUNO, JUICE), it is almost impossible to think of a technical design on the surface to provide sufficient power to operate a lander system (or even an ice-penetrating probe). Thus, solar cells can not be considered as a primary power source for icy moon missions.

Several types of radioisotope thermal generators (RTGs) have been used for deep space missions (Fraser 2018) like the GPHS (e.g. Galileo, Cassini) or the MHW (Voyager). At begin of life (BOL), those RTGs provided about 290 and $156 \mathrm{~W}$ electrically, respectively. A new RTG generation (the MMRTG) produces about $2 \mathrm{~kW}$ of thermal power and $120 \mathrm{~W}$ of electric power at BOL, contains about $4.8 \mathrm{~kg}$ of ${ }^{238} \mathrm{PuO}_{2}$ and has an overall mass of $45 \mathrm{~kg}$ (Hammel et al. 2009). It is, thus, hardly conceivable, to power a melting probe electrically via a harness, with MMRTGs aboard the surface station. Even using the heat, generated by the decay of ${ }^{238} \mathrm{Pu}$ directly will not be sufficient to operate an ice-melting probe, keeping in mind a minimum requirement of protective housing for the pellets and the resulting power 
Table 2 Available radioisotopes for RHUs and RTGs

\begin{tabular}{lclll}
\hline Isotope & $\begin{array}{l}\text { Half life } \\
{[\mathrm{yrs}]}\end{array}$ & Radiation & $\begin{array}{l}\text { Specific thermal } \\
\text { power BOL [W/g] }\end{array}$ & $\begin{array}{l}\text { Specific thermal power } \\
\text { after 6 yrs [W/g] }\end{array}$ \\
\hline${ }^{210} \mathrm{Po}$ & 0.37 & $\alpha,(\gamma)$ & 141.0 & 0.00 \\
${ }^{238} \mathrm{Pu}$ & 87.7 & $\alpha,(\gamma)$ & 0.56 & 0.52 \\
${ }^{90} \mathrm{Sr}$ & 28.8 & $\beta$ & 0.93 & 0.76 \\
${ }^{85} \mathrm{Kr}$ & 10.8 & $\beta,(\gamma)$ & 0.62 & 0.36 \\
${ }^{60} \mathrm{Co}$ & 5.27 & $\beta, \gamma$ & 17.7 & 5.7 \\
${ }^{244} \mathrm{Cm}$ & 18.1 & $\alpha,(\gamma)$ & 2.83 & 2.03 \\
${ }^{241} \mathrm{Am}$ & 432.2 & $\alpha, \gamma$ & 0.11 & 0.11 \\
\hline
\end{tabular}

per volume. Note that a ${ }^{238} \mathrm{Pu}$ heat source placed on the surface of Europa (or Enceladus), on purpose or by accident, would not melt into the ice (Lorenz 2012).

It may be considered to use other radioisotopes than Plutonium, with higher specific power due to a shorter half life. Table 2 gives a short overview of some radioactive isotopes that may be used for space missions (Ulamec et al. 2010).

So far, only ${ }^{210} \mathrm{Po}$-based (Lunokhod) and ${ }^{238} \mathrm{Pu}$-based RHU/RTGs have spaceflight heritage. Strontium ${ }^{90} \mathrm{Sr}$ is used for some terrestrial RTG applications (e.g. for remote lighthouses) but requires considerably more shielding (factor 60) than e.g. ${ }^{238} \mathrm{Pu}$, due to the beta radiation and the resulting bremsstrahlung; also the daughter product, Yttrium ${ }^{90} \mathrm{Y}$, is a strong beta emitter. Strontium has been suggested, e.g., in the frame of the VALYRIE proposal (Stone et al. 2018a). ${ }^{210} \mathrm{Po}$, despite of its high specific power at BOL, is not favorable for a mission to the outer solar system, where the transfer alone takes many years, due to its short half-life. Therefore, also RTGs are hardly usable to power an ice-penetrating probe on Europa or Enceladus.

Another solution, that would indeed provide sufficient power could be to place a nuclear reactor on the surface, close to the melting location. Obviously, the transport and operations of such infrastructure has significant challenges. Reactors do have space heritage, however only in Earth orbit (El-Genk 2009). In the former Soviet Union, "BUK" power systems with $\mathrm{SiGe}$ thermoelectric conversion and fast neutron energy spectrum reactors were used for a total of 31 Satellites (RORSATs) from 1970 to 1988 and two TOPAZ reactors, with incore thermionic conversion and epithermal neutron energy spectrum, were used for Cosmos missions (1818 and 1867), launched in 1987 into about 800-km orbits. In the USA, the SNAP-10A system, with SiGe energy conversion and a thermal neutron energy spectrum reactor, was launched in 1965 into a 1300-km orbit (El-Genk 2009). All three systems used liquid $\mathrm{NaK}$ to cool the reactor. The SNAP-10A reactor was intended to produce $500 \mathrm{~W}$ of electric power for one year (but had to be shut down after 43 days for reasons not related to the reactor). The TOPAZ system (Fig. 15) was designed to provide an electric power of about $5.5 \mathrm{~kW}$ and a life time of up to one year. The mass of the reactor was about $320 \mathrm{~kg}$ and the complete system had a mass of about $980 \mathrm{~kg}$. The Soviet YENISEI (TOPAZ II) reactor, designed for longer life-times, has never been flown.

The Soviet program for developing reactors for space applications has been stopped in 1988, however, there is renewed interest in this technology in recent years. E.g., the European Commission has been funding the DEMOKRITOS project, preparing for a mega-watt class nuclear electric space propulsion flagship mission (Jansen et al. 2016). The Keldysh Research Centre in Russia manages in cooperation with Roskosmos, Rosatom and the Russian Academy of Sciences the transportation module as a nuclear power and propulsion 
Fig. 15 Nuclear power plant with thermionic reactors for space applications "Topaz" (from Kraus and Shabalin (2013))

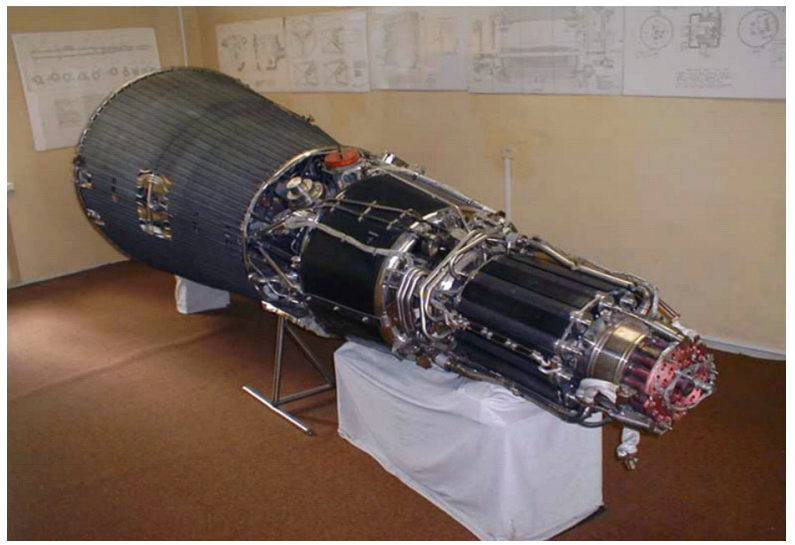

system (Koroteev et al. 2013). Activities at NASA to develop a 1-10 kW (electric) reactor for space applications are described, e.g., by Gibson et al. (2017).

Being far from $100 \%$ in efficiency, high-power nuclear reactors in space require large radiators to dissipate waste heat. The regulation of the reactor and the generation of electric power by a fully autonomous system is demanding. Nevertheless, in principle, such systems can be realized and will probably become relevant when a permanently staffed station on the surface of the Moon or human missions to Mars are realized.

\subsection{Communications}

One challenge of any mission to the oceans of the outer solar system is communications with the Earth. To establish a telemetry and telecommand link with a landed surface station on the surface of Europa or Enceladus is demanding by itself. Relay via an orbiter, either around the moon or in the Jovian or Saturnian system most likely is the preferred solution. Here, we concentrate on the challenges to receive telemetry from the probe within the ice (or through the ice from the ocean). Terrestrial ice-penetrating probes can employ tethers to transmit power and data. Due to losses in the cable and mass/volume issues, such tethered systems are practically limited to relatively shallow exploration depths of the order of a few kilometers. There is also a significant danger of tearing of the tether after the re-freezing of the ice-channel, due to tidal flexing. RF communications could be a solution through clear water or ice, however, the attenuation is dramatically increased in the presence of salts in the water. A solution could be the use of high-power transmitters and very low frequencies. Figure 16 shows the propagation distance (defined as $100 \mathrm{~dB}$ attenuation) of radio waves in fresh water and standard sea water, respectively. A signal with $10 \mathrm{kHz}$ can only penetrate some tens of meters in salt water. It has therefore been considered to deploy relay transceiver pods behind the probe as it melts through Europa's surface (Bryant 2002). However, this raises new challenges regarding the number of relay stations, their power supply, and their thermal control.

Submarines on Earth use either acoustic communications (with submarine receivers that are connected via cable to coast), raise antennas to the surface or use systems transmitting extremely low frequencies $(3-30 \mathrm{~Hz})$. The antenna design for such systems is demanding and signals can be transmitted only from base to ship and only with very low data rates (Belov and Hrynchuk 2017). Clearly, this is not a feasible option for an interplanetary mission. Radio waves are attenuated much less in ice than in (salt-) water, so communications 


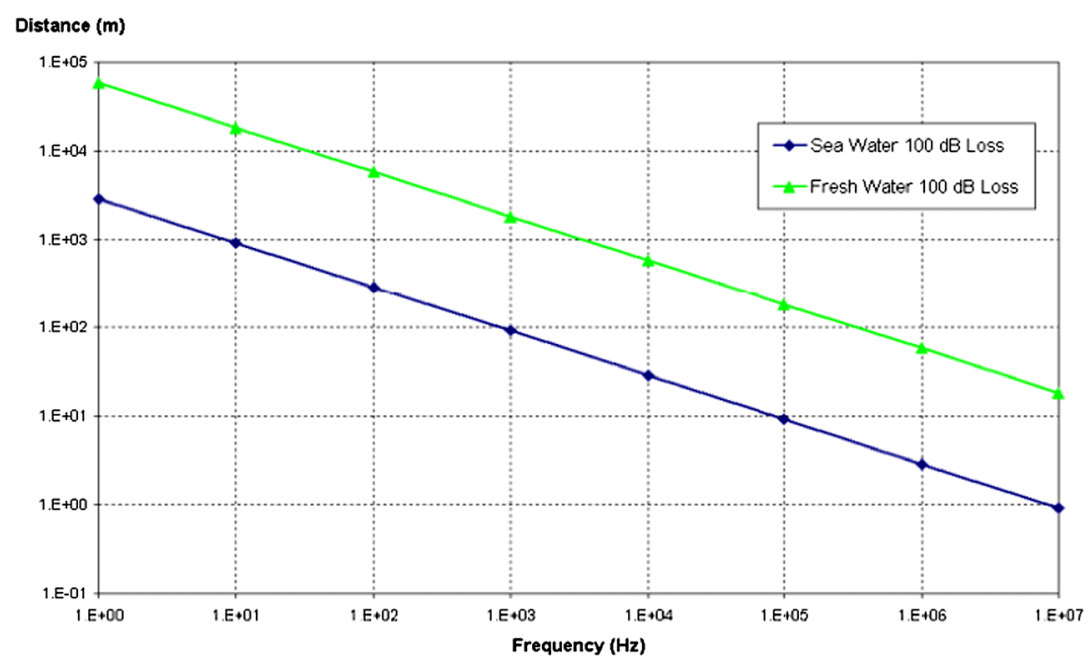

Fig. 16 Propagation distance (100 dB attenuation) in water as a function of frequency (from Palmeiro et al. (2011))

may be considered when the probe is still embedded in the ice, before submerging the ocean. Mätzler and Wegmüller (1987) have performed measurements of the real and the imaginary part of the dielectric constant $\varepsilon^{\prime}+i \varepsilon^{\prime \prime}$ of ice at temperatures between 0 and $-30{ }^{\circ} \mathrm{C}$, showing a very weak temperature dependency of $\varepsilon^{\prime}$, and a (strong) frequency dependency of $\varepsilon^{\prime \prime}$ (responsible for attenuation). As summarized by Bryant (2002) (and the references therein), $\varepsilon^{\prime \prime}$ has a minimum at around $1 \mathrm{GHz}$ and a temperature dependency leading to lower values with lower temperatures. $(1 / e)$ penetration depth in pure ice is in the range of $100 \mathrm{~m}$ around $-20{ }^{\circ} \mathrm{C}$ and in the range of kilometers at $-60{ }^{\circ} \mathrm{C}$ (there are no measurement points at lower temperatures). However, attenuation is higher for impure ices (containing salts) and on greater distances effects of cracks or dust layers will lead to refraction and weakening of signals. Bryant proposes the use of a number ( 7 to 35 to reach $10 \mathrm{~km}$ depth) of transceivers placed between the ice-probe and the surface (but does not enter a detailed discussion on how these could be deployed or powered).

It appears, at the moment, despite a number of technical issues (mass and volume, tether storage, deployment, electrical losses, durability, danger to break the tether, e.g., due to tidal stresses), that the use of a tether (including a coaxial cable and/or optical fibers) is the most promising solution. Work to assess the usability of tethers for communication and to increase their technology readiness level has already been started by McCarthy et al. (2019).

\subsection{Pressure Resistance}

The subsurface pressure $p$ for a celestial body under the ice or liquid can easily calculated by applying the formula $p=\rho g d$, when assuming a density for ice or ocean water (with $\rho$ being the density, $g$ the acceleration of gravity and $d$ the depth). In order to get an estimate for the design of an ice-penetrating probe or an underwater vehicle, it is sufficiently accurate to assume $\rho \approx 1000 \mathrm{~kg} / \mathrm{m}^{3}$. For an exact calculation of the pressure the effect of density variation due to composition (e.g. salinity or dust inclusions in the ice), crystalline structure of the ice, as well as compressibility needs to be estimated. The variation of $g$ with depth can be ignored in this context (for Enceladus, in a depth of $10 \mathrm{~km}, g$ is reduced by about only 
5\%). So, as example, in $10 \mathrm{~km}$ depth, the pressure on Europa is about $13 \mathrm{MPa}$, on Enceladus about 1.1 MPa and on Earth almost $100 \mathrm{MPa}$ (the deepest area in the terrestrial ocean). The pressure value may be much less, if the melting probe is encapsulated in a closed cavity in the ice, separated from the water column above.

There is a lot of experience in handling pressures in the tens of MPa range applied to submarines or off-shore equipment. Steel hulls of (military) submarines typically withstand pressures of about $5 \mathrm{MPa}$ (corresponding to a diving depth of $500 \mathrm{~m}$ ). For greater depths, either titanium is used, or bathyscaphes with a spherical hull and very thick walls (e.g. the Trieste, reaching the bottom of the Mariana trench including a pressure sphere designed with a wall thickness of 128-179 mm of steel (Walsh 1962). Tubes will fail either by yield or, in practice and at much lower pressures, by buckling. Generally it needs to be noted that withstanding pressures on the range of several $\mathrm{MPa}$ is not trivial and requires considerable effort to stiffen the walls of an ice-penetrating probe or an underwater vehicle. The alternative to thick walls protecting a "dry" interior is to have the probe internally pressurized, e.g. by filling it with melt water or silicone oil. Such a "wet" architecture has been used, for example, in the Philberth and AWI probes (for the tether storage canister section of the probe).

An aspect that must be considered is the pressure transient when reaching the ice-water interface. Although this pressure jump should not occur if ice and water are both in hydrostatic equilibrium, it has been observed on Earth by Tüg (2002) (Ulamec et al. 2007). Aamot (1968) also reported measurements of pressure jumps during stopping or restarting the probe of up to $8.8 \mathrm{MPa}$ due to freezing or melting of surrounding material with associated volume and pressure changes.

\subsection{Radiation Hardness}

Europa is orbiting within Jupiter's intense radiation belts, thus resulting in a severe radiation environment, depending on the exact landing location and being more severe at trailing edge than at the leading edge (Paranicas et al. 2009). As it can be seen in Fig. 17, however, radiation rapidly decreases with depth. Nordheim et al. (2018) have analyzed the dose for energetic particles for various depths of water and different locations on Europa in context with potential biosignatures. While the dose at the surface is in the range of $100 \mathrm{kGy} / \mathrm{d}$ (equal to $10000 \mathrm{krad} / \mathrm{d}$ ), this enormous value decreases by about eight orders of magnitudes below $1 \mathrm{~m}$ of water/ice. But at least before being covered with ice, any component aboard a Europa spacecraft will be exposed to high levels of radiation, thus requiring extensive radiation hardness, shielding, and fault protection. If an internal radioisotope power source is used, spacecraft components also have to be shielded from its radiation.

Since the magnetic moment of Saturn is about 60 times smaller than the one of Jupiter, radiation at Enceladus is a less severe problem than at Europa. On the surface of Enceladus, the radiation dose is about three orders of magnitude lower than on Europa (derived from Nordheim et al. (2018)).

While there is some literature on the scientific aspects of the radiation environment at the icy moons, there is considerably less available literature on the engineering implications. The issue of coping with the harsh radiation environment, however, is addressed in context with the development of NASA's Europa Clipper mission (Phillips and Pappalardo 2014), NASA's Europa Lander study (Hand et al. 2017), as well as ESA's JUICE mission (Grasset et al. 2013), which both plan for multiple Europa flybys. 


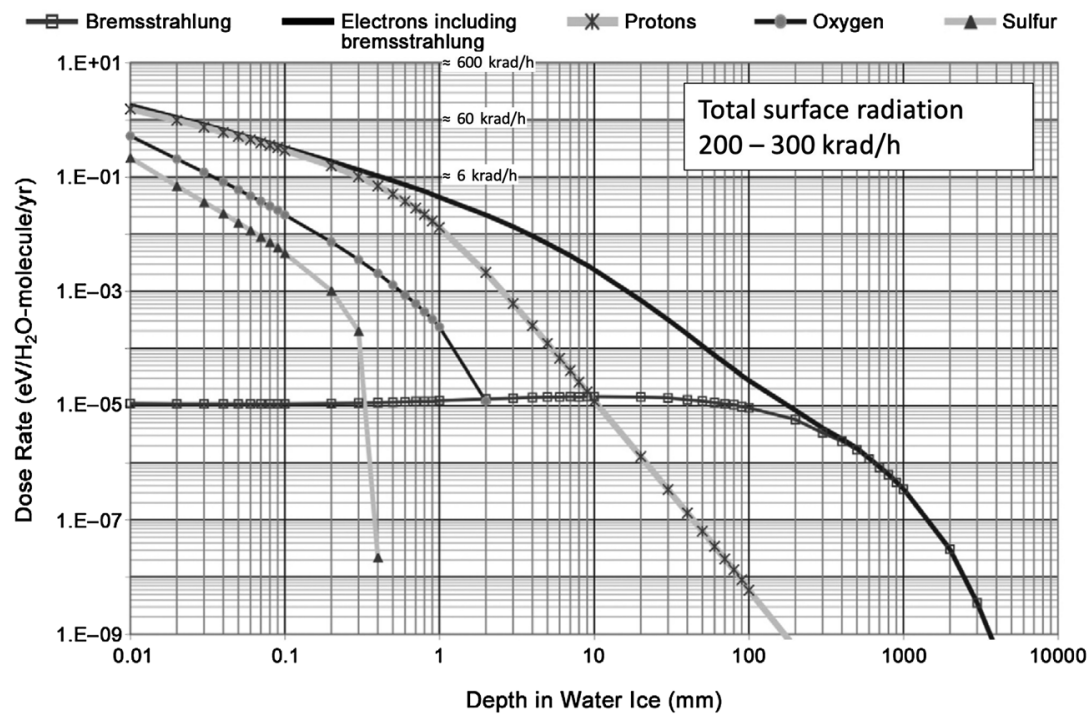

Fig. 17 Predicted dose rate vs. depth at the apex of Europa's trailing hemisphere by charged species using an input spectrum for various species and an ice surface. Heavy ions are stopped almost immediately in the water ice. At large depths, the electron dose rate becomes dominated by the contribution from secondaries (bremsstrahlung), adapted from Paranicas et al. (2009). 200-300 krad/h equal 2-3 kGy/h

\subsection{Corrosion}

Corrosion of the surface material of the ice-penetrating probe and an underwater vehicle is an aspect to be considered, particularly in light of our ignorance regarding the salinity or $\mathrm{pH}$ value of the ocean. Harrar et al. (1977), e.g., have analyzed the corrosion of various materials in geothermal, highly saline brines, which could be seen as the best terrestrial analogue. The risk of corrosion must be mitigated by a careful selection of the surface material or coatings. Materials like stainless steel and titanium are sufficiently resistant against corrosion in brines (even with high salinity and at high temperatures). Electronics, sensors, connectors, etc., have to be protected from the ocean liquid, e.g. by appropriate coatings like Teflon ${ }^{\circledR}$ or resins.

\subsection{Navigation}

Navigation is required for missions that penetrate the surface (Kowalski et al. 2016), and even more so when they shall explore the ocean beneath the ice shell. Navigation on an icy moon is very challenging, given that no natural external references exist other than the local gravity vector and the magnetic field vector at the surface. Generally, one has to distinguish between the navigation of an ice-penetrating probe and the navigation of an underwater vehicle. A probe that is connected to the surface via a tether could measure the propagated way, and thus, when combined with a tilt-measuring accelerometer, derive the depth from the surface. When reaching the liquid ocean, pressure sensors could give depth information.

One additional navigation aid within an ice-penetration probe or an underwater vehicle could be an inertial measurement unit (IMU), which measures the orientation of the probe/vehicle. If the attitude and the velocity over time are known, the trajectory of the probe/vehicle can be determined (or, more precisely, estimated). The disadvantage of IMUs 
is their drift on relatively short timescales, so that regular updates from external references are required. One potential artificial external reference concept that allows relative navigation between two (or more) elements of an under-ice system could be the deployment of an acoustic (or electromagnetic) transponder network that allows the estimation of positions via trilateration. Any communications system could be upgraded with such a transponder system (receiving and returning acoustic or electromagnetic pulses with time-stamp), thus allowing range information between the ice-penetrating probe and the surface station and between the base station at the ocean-entry point and the underwater vehicle. Due to attenuation, the range of signals in ice and water is limited. In both media, attenuation and wave propagation speed are strongly affected by the currently unknown salinity and particle content (whereby impurities such as cracks and bubbles are additional factors in ice). Therefore, unless the acoustic system is self-calibrating, navigation must be based on estimated values and is consequently less accurate. If there was more than one fixed transponder, even some kind of USBL (ultra-short baseline) navigation would be possible. Releasing a transponder to the bottom of the ocean could be considered. This would give a second reference point but the exact lateral position would be uncertain. A set-up with transponders at known locations (like in terrestrial oceans) would probably go far beyond the scope of a first mission to explore the oceans of Europa or Enceladus. The variable magnetic field can only be used as an additional relative external reference with respect to a lander / base station, if the latter also carries a magnetometer.

\subsection{Miniaturization}

It is a general concern for space missions to minimize the mass and volume of systems and instruments because the transport of every kilogram to an icy moon requires dozens of kilograms of propellant and structural mass. It also needs to be considered, however, that the laws of physics and the principles of technology set limits for the miniaturization of systems and instruments. An ice-melting probe of a given size, for example, as described in Sect. 4.4.1, requires a minimum power for efficient melting by minimizing conductive losses into the surrounding ice (i.e. melting a small volume of ice in front of the probe instead of just heating the surrounding large volume of ice). An extremely small "point-size-like" icemelting probe would still face the issue of losses, but requires an unrealistically high power density (note that losses by conduction are proportional to the surface area of the probe while required power density is proportional to the volume of the heater element). Also, electric power supply via a cable requires a certain thickness to avoid high resistivity losses, so that very thin cables or small tether containers are not advisable. Therefore, ice-melting probes with a diameter $\lesssim 5 \mathrm{~cm}$ would become very inefficient. For the instrumentation inside a probe, however, the situation is different and it is indeed advantageous to find ways to integrate small and lightweight devices. The same applies for subsystems, like RF communications devices (if applicable) or sensors for navigation and attitude control.

\subsection{Cleaning and Sterilization}

In-situ investigation of icy moons with the aim to search for organics, potential biomarkers, or even signs of past or present life requires a strict control of biological and organic contamination. COSPAR (Committee on Space Research) maintains and promulgates a planetary protection policy (Kminek et al. 2017) for the reference of spacefaring nations, both as an international standard on procedures to avoid organic constituent and biological contamination in space exploration, and to provide accepted guidelines and requirements in this area 
to guide compliance with the wording of the Outer Space Treaty (United Nations Office for Outer Space Affairs 1966). Different planetary protection categories (I-V) reflect the level of interest and concern that contamination can compromise future investigations or Earth's safety; the categories and associated requirements depend on the target body and mission type combinations.

On Earth, microorganisms are found almost everywhere. They are an integral component of our natural environment. The estimated total number of bacterial and archaeal cells on Earth is about $1.2 \times 10^{30}$ (Flemming and Wuertz 2019). Microorganisms are living in diverse habitats ranging from the deep oceanic and continental subsurface up to several kilometers in the atmosphere. Extremophilic microorganisms can withstand desiccating conditions, highintensity UV radiation, high salt concentrations, oxidizing compounds, high and low $\mathrm{pH}$ values, high and low temperatures, high and low pressure, and even the vacuum of space. They are also colonizing plants and animals including humans. Consequently, microorganisms are present in spacecraft assembly cleanrooms, even if these cleanrooms are subjected to standardised cleaning regimes with restricted access, air filtration, and constant temperature and humidity. For space missions with life detection instruments spacecraft assembly cleanrooms are also biologically controlled. The majority of microorganisms are introduced into cleanrooms by humans followed by microorganisms originating from ground support equipment and from the environment of the cleanroom (Moissl-Eichinger et al. 2012, 2015, 2016; Koskinen et al. 2017). The assembly, integration and testing of space hardware with planetary protection requirements has to be planned carefully. The space hardware has to be cleaned and sterilised with accepted methods and the bioburden has to be measured with specific assays (Fig. 18). The European Cooperation for Space Standardization (ECSS, https://ecss.nl/) has developed standards which are mandatory for ESA and NASA missions:

- ECSS-Q-ST-70-58: "Space product assurance - bioburden control of cleanrooms" describes how to control the bioburden in cleanrooms.

- ECSS-Q-ST-70-55: "Space product assurance - microbial examination of flight hardware and cleanrooms" describes how to measure the bioburden and biodiversity of spacecraft and cleanrooms.

- ECSS-Q-ST-70-53: "Space product assurance - materials and hardware compatibility tests for sterilization processes" describes how to test the suitability of different sterilisation methods for different materials.

- ECSS-Q-ST-70-57: "Space product assurance - dry heat bioburden reduction of flight hardware" describes how to sterilise hardware with dry heat.

- ECSS-Q-ST-70-56: "Space product assurance - vapour phase bioburden reduction of flight hardware" describes to how to sterilise hardware with hydrogen peroxide vapour.

COSPAR regulations do not define acceptable levels of organic contamination. Modelling of environmental conditions and contamination evolution over a mission's lifespan is necessary to calculate acceptable starting limits of contamination at launch depending on the target body, the specific objectives of a space mission and the instrument's sensitivity.

In a similar way as the COSPAR planetary protection policy and guidelines, SCAR (Scientific Committee on Antarctic Research) has formulated a code of conduct, which provides guidance to the scientific community with interests in exploring an conducting research on and in Antarctic subglacial aquatic environments. However, quantitative bioburden limits and detection assays were not specified (Siegert and Kennicutt 2018). 

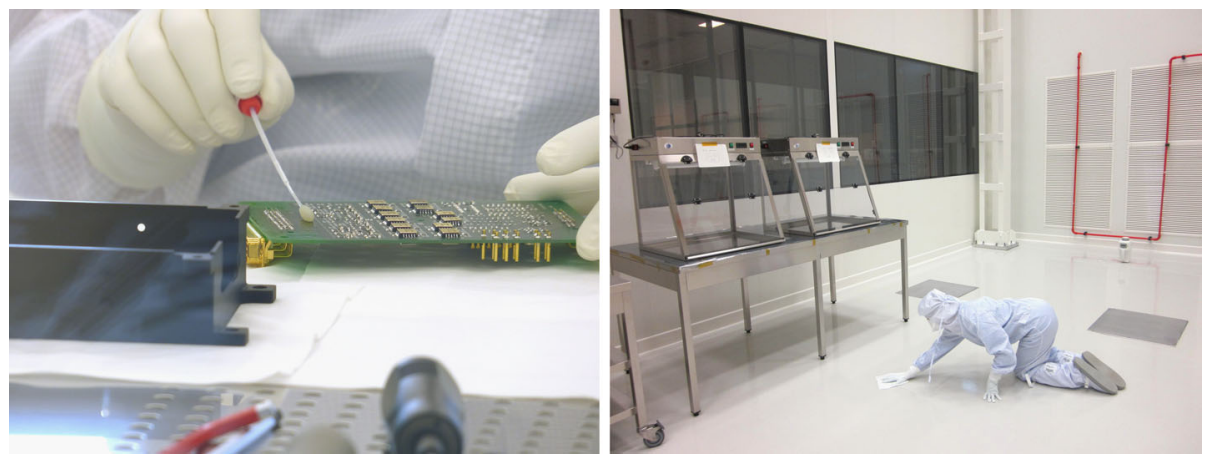

Fig. 18 Spacecraft hardware and cleanroom sampling with swabs and wipes

\section{Summary and Outlook}

The subsurface exploration of ocean worlds is an endeavor with many challenges. Before it can be realized, engineers have to advance current technology in a number of areas. In some of these, like miniaturization, artificial intelligence, or collaborative robotics, technological progress will take place independently of space exploration due to the multitude of terrestrial applications. Others, however, like the development of high-performance tethers or the required sensors and sampling methods, are rather application-specific. We have to emphasize that many of the necessary developments do not follow Moore's law (predicting the exponential technological advancements to which we got so used to in the last decades, although it has never been valid in space exploration) because they are not operating at the limits of technology but the limits of physics, like power generation and communication. The future development of such missions requires a collaboration of more disciplines than only space engineering. The expertise of engineers from the field of ocean engineering and scientists working in analog terrestrial environments like subglacial lakes is crucial for the successful implementation of extremely demanding missions such as the exploration of the oceans of the outer planet's moons. This high effort is rewarded with the unique chance of finding life that has developed independently from Earth, a discovery that would revolutionize not only science but many facets of human self-perception and our view of the world.

Acknowledgements Open Access funding provided by Projekt DEAL. We thank the anonymous reviewers for their many valuable comments for improving the manuscript. We would also like to thank the International Space Science Institute (ISSI) and in particular the organizers and sponsors of the workshop "ExoOceans: Space Exploration of the Outer Solar System Icy Moons Oceans" for making this work possible. Work by FP was funded by the European Research Council (ERC) Consolidator Grant 724908-Habitat OASIS.

Publisher's Note Springer Nature remains neutral with regard to jurisdictional claims in published maps and institutional affiliations.

Open Access This article is licensed under a Creative Commons Attribution 4.0 International License, which permits use, sharing, adaptation, distribution and reproduction in any medium or format, as long as you give appropriate credit to the original author(s) and the source, provide a link to the Creative Commons licence, and indicate if changes were made. The images or other third party material in this article are included in the article's Creative Commons licence, unless indicated otherwise in a credit line to the material. If material is not included in the article's Creative Commons licence and your intended use is not permitted by statutory regulation or exceeds the permitted use, you will need to obtain permission directly from the copyright holder. To view a copy of this licence, visit http://creativecommons.org/licenses/by/4.0/. 


\section{References}

H.W.C. Aamot, Heat transfer and performance analysis of a thermal probe for glaciers. Technical Report CRREL Special Report 194, Cold Regions Research \& Engineering Laboratory, Hanover (1967)

H.W.C. Aamot, Instrumented probes for deep glacial investigations. Technical report. U.S. Army Materiel Command, Cold Regions Research \& Engineering Laboratory (1968)

J. Aguzzi, M.M. Flexas, S. Flögel, C. Lo Iacono, M. Tangherlini, C. Costa, S. Marini, N. Bahamon, S. Martini, E. Fanelli, R. Danovaro, S. Stefanni, L. Thomsen, G. Riccobene, M. Hildebrandt, I. Masmitja, J. Del Rio, E.B. Clark, A. Branch, P. Weiss, A.T. Klesh, M.P. Schodlok, Exo-ocean exploration with deep-sea sensor and platform technologies. Astrobiology (2020). https://doi.org/10.1089/ast.2019.2129

M.F. A'Hearn, M.J.S. Belton, W.A. Delamere, J. Kissel, K.P. Klaasen, L.A. McFadden, K.J. Meech, H.J. Melosh, P.H. Schultz, J.M. Sunshine, P.C. Thomas, J. Veverka, D.K. Yeomans, M.W. Baca, I. Busko, C.J. Crockett, S.M. Collins, M. Desnoyer, C.A. Eberhardy, C.M. Ernst, T.L. Farnham, L. Feaga, O. Groussin, D. Hampton, S.I. Ipatov, J.-Y. Li, D. Lindler, C.M. Lisse, N. Mastrodemos, W.M. Owen, J.E. Richardson, D.D. Wellnitz, R.L. White, Deep impact: excavating comet Tempel 1. Science 310(5746), 258-264 (2005). https://doi.org/10.1126/science.1118923

A. Arora, P.M. Furlong, R. Fitch, S. Sukkarieh, T. Fong, Multi-modal active perception for information gathering in science missions. Auton. Robots 43(7), 1827-1853 (2019). https://doi.org/10.1007/ s10514-019-09836-5

Y. Bar-Cohen, K. Zacny, Drilling in Extreme Environments: Penetration and Sampling on Earth and Other Planets (Wiley, New York, 2009)

V.S. Belov, V.V. Hrynchuk, Communication Systems for Ultra-long Wave Bands (ELF and VLF). PhD thesis, Vinnytsia National Technical University (2017). (In Ukranian)

D.F. Berisford, J. Leichty, A. Klesh, K.P. Hand, Remote under-ice roving in Alaska with the buoyant rover for under-ice exploration, in AGU Fall Meeting Abstracts (2013)

M. Beuthe, Spatial patterns of tidal heating. Icarus 223(1), 308-329 (2013). https://doi.org/10.1016/ j.icarus.2012.11.020

M. Beuthe, Tides on Europa: the membrane paradigm. Icarus 248, 109-134 (2015). https://doi.org/10.1016/ j.icarus.2014.10.027

E.B. Bierhaus, K. Zahnle, C.R. Chapman, R.T. Pappalardo, W.R. McKinnon, K.K. Khurana, Europa's crater distributions and surface ages, in Europa, ed. by R.T. Pappalardo, W.B. McKinnon, K.K. Khurana (University of Arizona Press, Tucson, 2009), pp. 161-180

E.B. Bierhaus, A.S. McEwen, D.W. Wade, B.A. Ivanov, A fortuitous impact experiment at Mars, in Lunar and Planetary Science Conference. Lunar and Planetary Institute Technical Report, vol. 44 (2013), p. 2800. LPI Contribution No. 1719

U. Böttger, S.A. Bulat, F. Hanke, S.G. Pavlov, M. Greiner-Bär, H.-W. Hübers, Identification of inorganic and organic inclusions in the subglacial Antarctic Lake Vostok ice with Raman spectroscopy. J. Raman Spectrosc. 48(11), 1503-1508 (2017). https://doi.org/10.1002/jrs.5142

A. Bouquet, C.R. Glein, J.H. Waite Jr., How adsorption affects the gas-ice partitioning of organics erupted from Enceladus. Astrophys. J. 873(1), 28 (2019). https://doi.org/10.3847/1538-4357/ab0100

A.D. Bowen, D.R. Yoerger, C.C. German, J.C. Kinsey, M.V. Jakuba, D. Gomez-Ibanez, C.L. Taylor, C. Machado, J.C. Howland, C.L. Kaiser, M. Heintz, C. Pontbriand, S. Suman, L. O'Hara, J. Bailey, C. Judge, G. McDonald, L.L. Whitcomb, C.J. McFarland, L. Mayer, Design of Nereid-ui: a remotely operated underwater vehicle for oceanographic access under ice, in 2014 Oceans-St. John's (IEEE Press, New York, 2014), pp. 1-6

J.A. Breier, C.S. Sheik, D. Gomez-Ibanez, R.T. Sayre-McCord, R. Sanger, C. Rauch, M. Coleman, S.A. Bennett, B.R. Cron, M. Li, C.R. German, B.M. Toner, G.J. Dick, A large volume particulate and water multi-sampler with in situ preservation for microbial and biogeochemical studies. Deep-Sea Res., Part 1, Oceanogr. Res. Pap. 94, 195-206 (2014). https://doi.org/10.1016/j.dsr.2014.08.008

S. Bryant, Ice-embedded transceivers for Europa cryobot communications, in Proceedings, IEEE Aerospace Conference, vol. 1 (2002), pp. 1-349-1-356. https://doi.org/10.1109/AERO.2002.1036854

R. Campen, J. Kowalski, W.B. Lyons, S. Tulaczyk, B. Dachwald, E. Pettit, K.A. Welch, J.A. Mikucki, Microbial diversity of an Antarctic subglacial community and high-resolution replicate sampling inform hydrological connectivity in a polar desert. Environ. Microbiol. 21, 2290-2306 (2019). https://doi.org/10.1111/1462-2920.14607

A.F. Cheng, P. Michel, M. Jutzi, A.S. Rivkin, A. Stickle, O. Barnouin, C. Ernst, J. Atchison, P. Pravec, D.C. Richardson, Asteroid impact \& deflection assessment mission: kinetic impactor. Planet. Space Sci. 121, 27-35 (2016). https://doi.org/10.1016/j.pss.2015.12.004

G. Choblet, G. Tobie, C. Sotin, M. Behounkova, O. Cadek, F. Postberg, O. Soucek, Powering prolonged hydrothermal activity inside Enceladus. Nat. Astron. 1(12), 841-847 (2017). https://doi.org/ $10.1038 / \mathrm{s} 41550-017-0289-8$ 
J.B. Corliss, J. Dymond, L.I. Gordon, J.M. Edmond, R.P. von Herzen, R.D. Ballard, K. Green, D. Williams, A. Bainbridge, K. Crane, T.H. van Andel, Submarine thermal springs on the Galápagos rift. Science 203(4385), 1073-1083 (1979). https://doi.org/10.1126/science.203.4385.1073

A. Coustenis, S.K. Atreya, T. Balint, R.H. Brown, M.K. Dougherty, F. Ferri, M. Fulchignoni, D. Gautier, R.A. Gowen, C.A. Griffith, L.I. Gurvits, R. Jaumann, Y. Langevin, M.R. Leese, J.I. Lunine, C.P. McKay, X. Moussas, I. Müller-Wodarg, F. Neubauer, T.C. Owen, F. Raulin, E.C. Sittler, F. Sohl, C. Sotin, G. Tobie, T. Tokano, E.P. Turtle, J.-E. Wahlund, J.H. Waite, K.H. Baines, J. Blamont, A.J. Coates, I. Dandouras, T. Krimigis, E. Lellouch, R.D. Lorenz, A. Morse, C.C. Porco, M. Hirtzig, J. Saur, T. Spilker, J.C. Zarnecki, E. Choi, N. Achilleos, R. Amils, P. Annan, D.H. Atkinson, Y. Bénilan, C. Bertucci, B. Bézard, G.L. Bjoraker, M. Blanc, L. Boireau, J. Bouman, M. Cabane, M.T. Capria, E. Chassefière, P. Coll, M. Combes, J.F. Cooper, A. Coradini, F. Crary, T. Cravens, I.A. Daglis, E. de Angelis, C. de Bergh, I. de Pater, C. Dunford, G. Durry, O. Dutuit, D. Fairbrother, F.M. Flasar, A.D. Fortes, R. Frampton, M. Fujimoto, M. Galand, O. Grasset, M. Grott, T. Haltigin, A. Herique, F. Hersant, H. Hussmann, W. Ip, R. Johnson, E. Kallio, S. Kempf, M. Knapmeyer, W. Kofman, R. Koop, T. Kostiuk, N. Krupp, M. Küppers, H. Lammer, L.-M. Lara, P. Lavvas, S. Le Mouélic, S. Lebonnois, S. Ledvina, J. Li, T.A. Livengood, R.M. Lopes, J.-J. Lopez-Moreno, D. Luz, P.R. Mahaffy, U. Mall, J. Martinez-Frias, B. Marty, T. McCord, C. Menor Salvan, A. Milillo, D.G. Mitchell, R. Modolo, O. Mousis, M. Nakamura, C.D. Neish, C.A. Nixon, D. Nna Mvondo, G. Orton, M. Paetzold, J. Pitman, S. Pogrebenko, W. Pollard, O. Prieto-Ballesteros, P. Rannou, K. Reh, L. Richter, F.T. Robb, R. Rodrigo, S. Rodriguez, P. Romani, M. Ruiz Bermejo, E.T. Sarris, P. Schenk, B. Schmitt, N. Schmitz, D. Schulze-Makuch, K. Schwingenschuh, A. Selig, B. Sicardy, L. Soderblom, L.J. Spilker, D. Stam, A. Steele, K. Stephan, D.F. Strobel, K. Szego, C. Szopa, R. Thissen, M.G. Tomasko, D. Toublanc, H. Vali, I. Vardavas, V. Vuitton, R.A. West, R. Yelle, E.F. Young, TandEM: Titan and Enceladus mission. Exp. Astron. 23(3), 893-946 (2009). https://doi.org/10.1007/s10686-008-9103-z

B. Dachwald, S. Ulamec, J. Biele, Clean in-situ subsurface exploration of icy environments in the Solar System, in Habitability of Other Planets and Satellites, ed. by J.-P. de Vera, J. Seckbach (Springer, New York, 2013), pp. 367-397. https://doi.org/10.1007/978-94-007-6546-7_20

B. Dachwald, J. Mikucki, S. Tulaczyk, I. Digel, C. Espe, M. Feldmann, G. Francke, J. Kowalski, C.Xu. IceMole, A maneuverable probe for clean in situ analysis and sampling of subsurface ice and subglacial aquatic ecosystems. Ann. Glaciol. 55(65), 14-22 (2014). https://doi.org/10.3189/2014AoG65A004

J.B. Dalton, Spectroscopy of icy moon surface materials. Space Sci. Rev. 153(1-4), 219-247 (2010). https://doi.org/10.1007/s11214-010-9658-7

J.B. Dalton, R. Mogul, H.K. Kagawa, S.L. Chan, C.S. Jamieson, Methodologies and techniques for detecting extraterrestrial (microbial) life. Astrobiology 3(3), 505-529 (2003)

J.-P. de Vera, the Life Detection Group of BIOMEX/BIOSIGN, A Systematic Way to Life Detection: Combining Field, Lab and Space Research in Low Earth Orbit (Springer, Berlin, 2019), pp. 111-122. https://doi.org/10.1007/978-3-319-96175-0_5

J.-P. de Vera, M. Alawi, T. Backhaus, M. Baqué, D. Billi, U. Böttger, T. Berger, M. Bohmeier, C. Cockell, R. Demets, R. de la Torre Noetzel, H. Edwards, A. Elsaesser, C. Fagliarone, A. Fiedler, B. Foing, F. Foucher, J. Fritz, F. Hanke, T. Herzog, G. Horneck, H.-W. Hübers, B. Huwe, J. Joshi, N. Kozyrovska, M. Kruchten, P. Lasch, N. Lee, S. Leuko, T. Leya, A. Lorek, J. Martínez-Frías, J. Meessen, S. Moritz, R. Moeller, K. Olsson-Francis, S. Onofri, S. Ott, C. Pacelli, O. Podolich, E. Rabbow, G. Reitz, P. Rettberg, O. Reva, L. Rothschild, L.G. Sancho, D. Schulze-Makuch, L. Selbmann, P. Serrano, U. Szewzyk, C. Verseux, J. Wadsworth, D. Wagner, F. Westall, D. Wolter, L. Zucconi, Limits of life and the habitability of Mars: the ESA space experiment BIOMEX on the ISS. Astrobiology 19(2), 145-157 (2019). https://doi.org/10.1089/ast.2018.1897

W.B. Durham, O. Prieto-Ballesteros, D.L. Goldsby, J.S. Kargel, Rheological and thermal properties of icy materials. Space Sci. Rev. 153(1-4), 273-298 (2010). https://doi.org/10.1007/s11214-009-9619-1

J. Eigenbrode, R.E. Gold, C.P. McKay, T. Hurford, A. Davila, Searching for life in an ocean world: the Enceladus Life Signatures And Habitability (ELSAH) mission concept, in 42nd COSPAR Scientific Assembly, vol. 42 (2018)

M.S. El-Genk, Deployment history and design considerations for space reactor power systems. Acta Astronaut. 64(9), 833-849 (2009). https://doi.org/10.1016/j.actaastro.2008.12.016

H. Fiebrich, J. Haines, F. Tonicello, Power system design of the Rosetta spacecraft, in 2nd International Energy Conversion Engineering Conference (2004). https://doi.org/10.2514/6.20045535. Paper AIAA 2004-5535

H.-C. Flemming, S. Wuertz, Bacteria and archaea on Earth and their abundance in biofilms. Nat. Rev. Microbiol. 17(4), 247-260 (2019). https://doi.org/10.1038/s41579-019-0158-9

S.D. Fraser, Exploration of the outer solar system: missions and their power systems exploration missions, in Outer Solar System: Prospective Energy and Material Resources, ed. by V. Badescu, K. Zacny (Springer, Berlin, 2018), pp. 823-836. https://doi.org/10.1007/978-3-319-73845-1_18 
F.E. Genceli, S. Horikawa, Y. Iizuka, T. Sakurai, T. Hondoh, T. Kawamura, G.-J. Witkamp, Meridianiite detected in ice. J. Glaciol. 55(189), 117-122 (2009). https://doi.org/10.3189/002214309788608921

C.R. German, D.R. Yoerger, M. Jakuba, T.M. Shank, C.H. Langmuir, K. Nakamura, Hydrothermal exploration with the autonomous benthic explorer. Deep-Sea Res., Part 1, Oceanogr. Res. Pap. 55(2), 203-219 (2008). https://doi.org/10.1016/j.dsr.2007.11.004

C.R. German, D.K. Blackman, A.T. Fisher, P.R. Girguis, K.P. Hand, T.M. Hoehler, J.A. Huber, J.C. Marshall, J. Seewald, E. Shock, C. Sotin, A.M. Thurnherr, B.M. Toner, Exploring ocean worlds: a systems-level approach for the search for life beyond Earth, in 2019 Astrobiology Science Conference, (Am. Geophys. Union, Washington, 2019a). https://agu.confex.com/agu/abscicon19/prelim.cgi/Paper/479936

L. German, J.A. Mikucki, S.A. Welch, K.A. Welch, A. Lutton, B. Dachwald, J. Kowalski, D. Heinen, M. Feldmann, G. Francke, C. Espe, W.B. Lyons, Validation of sampling Antarctic subglacial hypersaline waters with an electrothermal ice melting probe (IceMole) for environmental analytical geochemistry. Int. J. Environ. Anal. Chem., 1-14 (2019b). https://doi.org/10.1080/03067319.2019.1704750

M.A. Gibson, S.R. Oleson, D.I. Poston, P. McClure, NASA's kilopower reactor development and the path to higher power missions, in 2017 IEEE Aerospace Conference (2017). https://doi.org/10.1109/ AERO.2017.7943946

C.R. Glein, J.A. Baross, J.H. Waite, The pH of Enceladus' ocean. Geochim. Cosmochim. Acta 162, 202-219 (2015). https://doi.org/10.1016/j.gca.2015.04.017

C.R. Glein, F. Postberg, S.D. Vance, The geochemistry of Enceladus: composition and controls, in Enceladus and the Icy Moons of Saturn (University of Arizona Press, Tucson, 2018), pp. 39-56. https://doi.org/10.2458/azu_uapress_9780816537075-ch003

J.D. Goguen, B.J. Buratti, R.H. Brown, R.N. Clark, P.D. Nicholson, M.M. Hedman, R.R. Howell, C. Sotin, D.P. Cruikshank, K.H. Baines, K.J. Lawrence, J.R. Spencer, D.G. Blackburn, The temperature and width of an active fissure on Enceladus measured with Cassini VIMS during the 14 April 2012 South Pole flyover. Icarus 226(1), 1128-1137 (2013). https://doi.org/10.1016/j.icarus.2013.07.012

R.A. Gowen, A. Smith, A.D. Fortes, S. Barber, P. Brown, P. Church, G. Collinson, A.J. Coates, G. Collins, I.A. Crawford, V. Dehant, J. Chela-Flores, A.D. Griffiths, P.M. Grindrod, L.I. Gurvits, A. Hagermann, H. Hussmann, R. Jaumann, A.P. Jones, K.H. Joy, O. Karatekin, K. Miljkovic, E. Palomba, W.T. Pike, O. Prieto-Ballesteros, F. Raulin, M.A. Sephton, S. Sheridan, M. Sims, M.C. Storrie-Lombardi, R. Ambrosi, J. Fielding, G. Fraser, Y. Gao, G.H. Jones, G. Kargl, W.J. Karl, A. Macagnano, A. Mukherjee, J.P. Muller, A. Phipps, D. Pullan, L. Richter, F. Sohl, J. Snape, J. Sykes, N. Wells, Penetrators for in situ subsurface investigations of Europa. Adv. Space Res. 48(4), 725-742 (2011). https://doi.org/ 10.1016/j.asr.2010.06.026

O. Grasset, M.K. Dougherty, A. Coustenis, E.J. Bunce, C. Erd, D. Titov, M. Blanc, A. Coates, P. Drossart, L.N. Fletcher, H. Hussmann, R. Jaumann, N. Krupp, J.-P. Lebreton, O. Prieto-Ballesteros, P. Tortora, F. Tosi, T. Van Hoolst, JUpiter ICy moons Explorer (JUICE): an ESA mission to orbit Ganymede and to characterise the Jupiter system. Planet. Space Sci. 78, 1-21 (2013). https://doi.org/10.1016/ j.pss.2012.12.002

M. Guzman, R. Lorenz, D. Hurley, W. Farrell, J. Spencer, C. Hansen, T. Hurford, J. Ibea, P. Carlson, C.P. McKay et al., Collecting amino acids in the Enceladus plume. Int. J. Astrobiol. 18(1), 47-59 (2019). https://doi.org/10.1017/S1473550417000544

T. Hammel, R. Bennett, W. Otting, S. Fanale, Multi-mission radioisotope thermoelectric generator (MMRTG) and performance prediction model, in 7th International Energy Conversion Engineering Conference (2009). https://doi.org/10.2514/6.2009-4576. Paper AIAA 2009-4576

K.P. Hand, A.E. Murray, J.B. Garvin, W.B. Brinckerhoff, B.C. Christner, K.S. Edgett, B.L. Ehlmann, C.R. German, A.G. Hayes, T.M. Hoehler, S.M. Horst, J.I. Lunine, K.H. Nealson, C. Paranicas, B.E. Schmidt, D.E. Smith, A.R. Rhoden, M.J. Russell, A.S. Templeton, P.A. Willis, R.A. Yingst, C.B. Phillips, M.L. Cable, K.L. Craft, A.E. Hofmann, T.A. Nordheim, R.P. Pappalardo, the Project Engineering Team, Report of the Europa Lander science definition team. Technical report, NASA/JPL (2017). https://europa.nasa.gov/resources/58/europa-lander-study-2016-report/

C.J. Hansen, L. Esposito, A.I.F. Stewart, J. Colwell, A. Hendrix, W. Pryor, D. Shemansky, R. West, Enceladus' water vapor plume. Science 311(5766), 1422-1425 (2006). https://doi.org/10.1126/science. 1121254

C.J. Hansen, L.W. Esposito, A.I.F. Stewart, B. Meinke, B. Wallis, J.E. Colwell, A.R. Hendrix, K. Larsen, W. Pryor, F. Tian, Water vapour jets inside the plume of gas leaving Enceladus. Nature 456, 477-479 (2008). https://doi.org/10.1038/nature07542

C.J. Hansen, L.W. Esposito, J.E. Colwell, A.R. Hendrix, G. Portyankina, A.I.F. Stewart, R.A. West, The composition and structure of Enceladus' plume from the complete set of Cassini UVIS occultation observations. Icarus 344, 113461 (2019). https://doi.org/10.1016/j.icarus.2019.113461 
J.E. Harrar, R.D. McCright, A. Goldberg, Field electrochemical measurements of corrosion characteristics of materials in hypersaline geothermal brine. Technical Report UCRL-52376 Lawrence Livermore Lab (1977)

M.M. Hedman, P.D. Nicholson, M.R. Showalter, R.H. Brown, B.J. Buratti, R.N. Clark, Spectral observations of the Enceladus plume with Cassini-VIMS. Astrophys. J. 693(2), 1749-1762 (2009). https://doi.org/10.1088/0004-637X/693/2/1749

M.M. Hedman, C.M. Gosmeyer, P.D. Nicholson, C. Sotin, R.H. Brown, R.N. Clark, K.H. Baines, B.J. Buratti, M.R. Showalter, An observed correlation between plume activity and tidal stresses on Enceladus. Nature 500(7461), 182-184 (2013). https://doi.org/10.1038/nature12371

D. Hemingway, L. Iess, R. Tajeddine, G. Tobie, The interior of Enceladus, in Enceladus and the Icy Moons of Saturn (University of Arizona Press, Tucson, 2018), pp. 57-77. https://doi.org/10.2458/ azu_uapress_9780816537075-ch004

A.R. Hendrix, T.A. Hurford, L.M. Barge, M.T. Bland, J.S. Bowman, W. Brinckerhoff, B.J. Buratti, M.L. Cable, J. Castillo-Rogez, G.C. Collins, S. Diniega, C.R. German, A.G. Hayes, T. Hoehler, S. Hosseini, C.J.A. Howett, A.S. McEwen, C.D. Neish, M. Neveu, T.A. Nordheim, G.W. Patterson, D.A. Patthoff, C. Phillips, A. Rhoden, B.E. Schmidt, K.N. Singer, J.M. Soderblom, S.D. Vance, The NASA roadmap to ocean worlds. Astrobiology 19(1), 1-27 (2019). https://doi.org/10.1089/ast.2018.1955

H.-W. Hsu, F. Postberg, Y. Sekine, T. Shibuya, S. Kempf, M. Horányi, A. Juhász, N. Altobelli, K. Suzuki, Y. Masaki, T. Kuwatani, S. Tachibana, S. Sirono, G. Moragas-Klostermeyer, R. Srama, Ongoing hydrothermal activities within Enceladus. Nature 519(7542), 207-210 (2015). https://doi.org/10.1038/ nature 14262

H. Hussmann, F. Sohl, T. Spohn, Subsurface oceans and deep interiors of medium-sized outer planet satellites and large trans-neptunian objects. Icarus 185(1), 258-273 (2006). https://doi.org/10.1016/ j.icarus.2006.06.005

L. Iess, D.J. Stevenson, M. Parisi, D. Hemingway, R.A. Jacobson, J.I. Lunine, F. Nimmo, J.W. Armstrong, S.W. Asmar, M. Ducci, P. Tortora, The gravity field and interior structure of Enceladus. Science 344(6179), 78-80 (2014). https://doi.org/10.1126/science.1250551

A.P. Ingersoll, S.P. Ewald, Decadal timescale variability of the Enceladus plumes inferred from Cassini images. Icarus 282, 260-275 (2017). https://doi.org/10.1016/j.icarus.2016.09.018

A.P. Ingersoll, M. Nakajima, Controlled boiling on Enceladus. 2. Model of the liquid-filled cracks. Icarus 272, 319-326 (2016). https://doi.org/10.1016/j.icarus.2015.12.040

A.P. Ingersoll, A.A. Pankine, Subsurface heat transfer on Enceladus: conditions under which melting occurs. Icarus 206(2), 594-607 (2010). https://doi.org/10.1016/j.icarus.2009.09.015

M.A. Ivanov, L.M. Prockter, B. Dalton, Landforms of Europa and selection of landing sites. Adv. Space Res. 48(4), 661-677 (2011). https://doi.org/10.1016/j.asr.2011.05.016

F. Jansen, W. Bauer, F. Masson, J.-M. Ruault, J.-C. Worm, E. Detsis, F. Lassoudiere, R. Granjon, E. Gaia, M.C. Tosi, S. Ferraris, A.S. Koroteev, A.V. Semenkin, A. Solodukhin, T. Tinsley, Z. Hodgson, C. Koppel, L.N.F. Guimaraes, DEMOCRITOS demonstrators for realization of nuclear electric propulsion of the European roadmaps MEGAHIT \& DiPoP. Trans. Jpn. Soc. Aeronaut. Space Sci., Aerosp. Technol. Jpn. 14(ists30), Pb_225-Pb_233 (2016). https://doi.org/10.2322/tastj.14.Pb_225

R. Jaumann, K. Stephan, G.B. Hansen, R.N. Clark, B.J. Buratti, R.H. Brown, K.H. Baines, S.F. Newman, G. Bellucci, G. Filacchione, A. Coradini, D.P. Cruikshank, C.A. Griffith, C.A. Hibbitts, T.B. McCord, R.M. Nelson, P.D. Nicholson, C. Sotin, R. Wagner, Distribution of icy particles across Enceladus' surface as derived from Cassini-VIMS measurements. Icarus 193(2), 407-419 (2008). https://doi.org/10.1016/j.icarus.2007.09.013

X. Jia, M.G. Kivelson, K.K. Khurana, WS. Kurth, Evidence of a plume on Europa from Galileo magnetic and plasma wave signatures. Nat. Astron. 2(6), 459-464 (2018). https://doi.org/10.1038/s41550-018-0450-Z

S. Kamata, F. Nimmo, Interior thermal state of Enceladus inferred from the viscoelastic state of the ice shell. Icarus 284, 387-393 (2017). https://doi.org/10.1016/j.icarus.2016.11.034

J.S. Kargel, The salt of Europa. Science 280(5367), 1211-1212 (1998). https://doi.org/10.1126/science. 280.5367.1211

S. Kempf, M. Horányi, H. Hsu, T.W. Hill, A. Juhász, H.T. Smith, Saturn's diffuse E ring and its connection with Enceladus, in Enceladus and the Icy Moons of Saturn (University of Arizona Press, Tucson, 2018), pp. 195-210. https://doi.org/10.2458/azu_uapress_9780816537075-ch010

N. Khawaja, F. Postberg, J. Hillier, F. Klenner, S. Kempf, L. Nölle, R. Reviol, Z. Zou, R. Srama, Low-mass nitrogen-, oxygen-bearing, and aromatic compounds in Enceladean ice grains. Mon. Not. R. Astron. Soc. 489(4), 5231-5243 (2019). https://doi.org/10.1093/mnras/stz2280

M.R. Kirchoff, E.B. Bierhaus, L. Dones, S.J. Robbins, K.N. Singer, R.J. Wagner, K.J. Zahnle, Cratering histories in the Saturnian system, in Enceladus and the Icy Moons of Saturn (University of Arizona Press, Tucson, 2018), pp. 267-284 
E.S. Kite, A.M. Rubin, Sustained eruptions on Enceladus explained by turbulent dissipation in tiger stripes. Proc. Natl. Acad. Sci. 113(15), 3972-3975 (2016). https://doi.org/10.1073/pnas.1520507113

F. Klenner, F. Postberg, J. Hillier, N. Khawaja, M. Cable, B. Abel, S. Kempf, C. Glein, J. Lunine, R. Hodyss, R. Reviol, F. Stolz, Discriminating abiotic and biotic fingerprints of amino acids and fatty acids in ice grains relevant to ocean worlds. Astrobiology 20(12) (2020a). https://doi.org/10.1089/ast.2019.2188

F. Klenner, F. Postberg, J. Hillier, N. Khawaja, R. Reviol, F. Stolz, M.L. Cable, B. Abel, L. Nölle, Analogue experiments for the identification of trace biosignatures in ice grains from extraterrestrial ocean worlds. Astrobiology 20(2) (2020b). https://doi.org/10.1089/ast.2019.2065

G. Kminek, C. Conley, V. Hipkin, H. Yano, COSPAR's planetary protection policy. Space Res. Today 200, 12-25 (2017). https://doi.org/10.1016/j.srt.2017.11.010

N.I. Kömle, P. Tiefenbacher, A. Kahr, Melting probe experiments under Mars surface conditions - the influence of dust layers, CO2-ice and porosity. Icarus 315, 7-19 (2018a). https://doi.org/10.1016/ j.icarus.2018.06.012

N.I. Kömle, P. Tiefenbacher, P. Weiss, A. Bendiukova, Melting probes revisited - ice penetration experiments under Mars surface pressure conditions. Icarus 308, 117-127 (2018b). https://doi.org/10.1016/ j.icarus.2017.08.006

K. Konstantinidis, C.L. Flores Martinez, B. Dachwald, A. Ohndorf, P. Dykta, P. Bowitz, M. Rudolph, I. Digel, J. Kowalski, K. Voigt, R. Förstner, A lander mission to probe subglacial water on Saturn's moon Enceladus for life. Acta Astronaut. 106, 63-89 (2014). https://doi.org/10.1016/j.actaastro.2014.09.012

A.S. Koroteev, V.N. Akimov, A.V. Semenkin, Nuclear power as the way to far space exploration - the Russian experience and the prospects for the growth, in MEGAHIT Workshop (2013)

K. Koskinen, P. Rettberg, R. Pukall, A. Auerbach, L. Wink, S. Barczyk, A. Perras, A. Mahnert, D. Margheritis, G. Kminek, C. Moissl-Eichinger, Microbial biodiversity assessment of the European Space Agency's ExoMars 2016 mission. Microbiome 5(1), 143 (2017). https://doi.org/10.1186/s40168-017-0358-3

J. Kowalski, P. Linder, S. Zierke, B. von Wulfen, J. Clemens, K. Konstantinidis, G. Ameres, R. Hoffmann, J. Mikucki, S. Tulaczyk, O. Funke, D. Blandfort, C. Espe, M. Feldmann, G. Francke, S. Hiecker, E. Plescher, S. Schöngarth, K. Schüller, B. Dachwald, I. Digel, G. Artmann, D. Eliseev, D. Heinen, F. Scholz, C. Wiebusch, S. Macht, U. Bestmann, T. Reineking, C. Zetzsche, K. Schill, R. Förstner, H. Niedermeier, A. Szumski, B. Eissfeller, U. Naumann, K. Helbing, Navigation technology for exploration of glacier ice with maneuverable melting probes. Cold Reg. Sci. Technol. 123, 53-70 (2016). https://doi.org/10.1016/j.coldregions.2015.11.006

E.I. Kraus, I.I. Shabalin, Impact loading of a space nuclear powerplant. Frattura Integr. Strutt. 7(24), 138-150 (2013). https://doi.org/10.3221/IGF-ESIS.24.15

G. Latham, M. Ewing, J. Dorman, F. Press, N. Toksoz, G. Sutton, R. Meissner, F. Duennebier, Y. Nakamura, R. Kovach, M. Yates, Seismic data from man-made impacts on the moon. Science 170(3958), 620-626 (1970). https://doi.org/10.1126/science.170.3958.620

J. Lawrence, B.E. Schmidt, M.R. Meister, D. Dichek, C. Ramey, B. Hurwitz, A. Spears, A. Mullen, F.E. Bryson, J.J. Lutz, J.P. Lawrence, J.B. Glass, A.M. Stockton, N.C. Speller, M. Cato, D. Block, M. Philleo, J.S. Bowman, E.K. Hamerton, J. Buffo, Life under ice: Antarctic Ocean world analogs with HROV icefin and RISE UP, in AGU Fall Meeting Abstracts (2018)

A. Le Gall, C. Leyrat, M.A. Janssen, G. Choblet, G. Tobie, O. Bourgeois, A. Lucas, C. Sotin, C. Howett, R. Kirk, R.D. Lorenz, R.D. West, A. Stolzenbach, M. Massé, A.H. Hayes, L. Bonnefoy, G. Veyssière, F. Paganelli, Thermally anomalous features in the subsurface of Enceladus's South polar terrain. Nat. Astron. 1(4), 0063 (2017). https://doi.org/10.1038/s41550-017-0063

K.L. Litwin, B.R. Zygielbaum, P.J. Polito, L.S. Sklar, G.C. Collins, Influence of temperature, composition, and grain size on the tensile failure of water ice: implications for erosion on Titan. J. Geophys. Res., Planets 117, E08013 (2012). https://doi.org/10.1029/2012JE004101

R.D. Lorenz, Planetary penetrators: their origins, history and future. Adv. Space Res. 38(3), 403-431 (2011). https://doi.org/10.1016/j.asr.2011.03.033

R.D. Lorenz, Thermal drilling in planetary ices: an analytic solution with application to planetary protection problems of radioisotope power sources. Astrobiology 12(8), 799-802 (2012). https://doi.org/10.1089/ast.2012.0816

R.D. Lorenz, W.V. Boynton, C.F. Turner, Demonstration of comet sample acquisition by penetrator, in IAA Conference on Low-Cost Planetary Exploration, vol. ESA Proceedings SP-542 (2003), pp. 387-394

J. Lunine, H. Waite, F. Postberg, L. Spilker, K. Clark, Enceladus Life Finder: the search for life in a habitable moon, in EGU General Assembly Conference Abstracts, vol. 17 (2015)

W.B. Lyons, J.A. Mikucki, L.A. German, K.A. Welch, S.A. Welch, C.B. Gardner, S.M. Tulaczyk, E.C. Pettit, J. Kowalski, B. Dachwald, The geochemistry of englacial brine from Taylor Glacier Antarctica. J. Geophys. Res., Biogeosci. 124(3), 633-648 (2019). https://doi.org/10.1029/2018JG004411 
L. Massarweh, P. Cappuccio, Sesion: space trajectory design and optimization I, in On the Restricted 3-Body Problem for the Saturn-Enceladus System: Mission Geometry and Orbit Design for Plume Sampling Missions (AIAA, Washington, 2020). https://doi.org/10.2514/6.2020-0467

C. Mätzler, U. Wegmüller, Dielectric properties of freshwater ice at microwave frequencies. J. Phys. D, Appl. Phys. 20(12), 1623-1630 (1987). https://doi.org/10.1088/0022-3727/20/12/013

T.C. McCarthy, K.L. Craft, C.R. German, M.V. Jakuba, R.D. Lorenz, G.W. Patterson, A. Rhoden, Europa STI: exploring communication techniques and strategies for sending signals through the ice (STI) for an ice-ocean probe, in Oceans Worlds, vol. 2019 (2019), p. 6023

T.B. McCord, G.B. Hansen, F.P. Fanale, R.W. Carlson, D.L. Matson, T.V. Johnson, W.D. Smythe, J.K. Crowley, P.D. Martin, A. Ocampo, C.A. Hibbitts, J.C. Granahan (the NIMS Team), Salts on Europa's surface detected by Galileo's near infrared mapping spectrometer. Science 280(5367), 1242-1245 (1998). https://doi.org/10.1126/science.280.5367.1242

J.M. McDermott, J.S. Seewald, C.R. German, S.P. Sylva, Pathways for abiotic organic synthesis at submarine hydrothermal fields. Proc. Natl. Acad. Sci. 112(25), 7668-7672 (2015). https://doi.org/ $10.1073 /$ pnas. 1506295112

C.P. McKay, Planetary protection for a Europa surface sample return: the Ice Clipper mission. Adv. Space Res. 30(6), 1601-1605 (2002). https://doi.org/10.1016/S0273-1177(02)00480-5

M. Meister, D. Dichek, A. Spears, B. Hurwitz, C. Ramey, J. Lawrence, K. Philleo, J. Lutz, J. Lawrence, B.E. Schmidt Icefin, Redesign and 2017 Antarctic field deployment, in OCEANS 2018 MTS/IEEE Charleston (2018), pp. 1-5. https://doi.org/10.1109/OCEANS.2018.8604725

G. Mitri, F. Postberg, J.M. Soderblom, P. Wurz, P. Tortora, B. Abel, J.W. Barnes, M. Berga, N. Carrasco, A. Coustenis, J.-P. Paul de Vera, A. D’Ottavio, F. Ferri, A.G. Hayes, P.O. Hayne, J.K. Hillier, S. Kempf, J.-P. Lebreton, R.D. Lorenz, A. Martelli, R. Orosei, A.E. Petropoulos, K. Reh, J. Schmidt, C. Sotin, R. Srama, G. Tobie, A. Vorburger, V. Vuitton, A. Wong, M. Zannoni, Explorer of Enceladus and Titan (E2T): investigating ocean worlds' evolution and habitability in the solar system. Planet. Space Sci. 155, 73-90 (2018). https://doi.org/10.1016/j.pss.2017.11.001

C. Moissl-Eichinger, P. Rettberg, R. Pukall, The first collection of spacecraft-associated microorganisms: a public source for extremotolerant microorganisms from spacecraft assembly clean rooms. Astrobiology 12(11), 1024-1034 (2012). https://doi.org/10.1089/ast.2012.0906

C. Moissl-Eichinger, A.K. Auerbach, A.J. Probst, A. Mahnert, L. Tom, Y. Piceno, G.L. Andersen, K. Venkateswaran, P. Rettberg, S. Barczyk, R. Pukall, G. Berg, Quo vadis? Microbial profiling revealed strong effects of cleanroom maintenance and routes of contamination in indoor environments. Sci. Rep. 5, 9156 (2015). https://doi.org/10.1038/srep09156

C. Moissl-Eichinger, C. Cockell, P. Rettberg, Venturing into new realms? Microorganisms in space. FEMS Microbiol. Rev. 40(5), 722-737 (2016). https://doi.org/10.1093/femsre/fuw015

M.H. Moore, R.L. Hudson, Ir detection of $\mathrm{H} 2 \mathrm{O} 2$ at $80 \mathrm{~K}$ in ion-irradiated laboratory ices relevant to Europa. Icarus 145(1), 282-288 (2000). https://doi.org/10.1006/icar.1999.6325

J.M. Moore, G. Black, B. Buratti, C.B. Phillips, J. Spencer, R. Sullivan, Surface properties, regolith, and landscape degradation, in Europa, ed. by R.T. Pappalardo, W.B. McKinnon, K.K. Khurana (University of Arizona Press, Tucson, 2009a), pp. 329-349

W.B. Moore, H. Hussmann, R.T. Pappalardo, W.B. McKinnon, K. Khurana, Thermal evolution of Europa's silicate interior, in Europa (University of Arizona Press, Tucson, 2009b), pp. 369-380

M. Mowlem, K. Saw, R. Brown, E. Waugh, C.L. Cardwell, J. Wyatt, I. Magiopoulos, P. Keen, J. Campbell, N. Rundle, A. Gkritzalis-Papadopoulos, Probe technologies for clean sampling and measurement of subglacial lakes. Philos. Trans. R. Soc. Lond. A 374(2059), 20150267 (2016). https://doi.org/ 10.1098/rsta.2015.0267

M. Nakajima, A.P. Ingersoll, Controlled boiling on Enceladus. 1. Model of the vapor-driven jets. Icarus 272, 309-318 (2016). https://doi.org/10.1016/j.icarus.2016.02.027

F. Nimmo, R.T. Pappalardo, Ocean worlds in the outer solar system. J. Geophys. Res., Planets 121(8), 13781399 (2016). https://doi.org/10.1002/2016JE005081

F. Nimmo, C. Porco, C. Mitchell, Tidally modulated eruptions on Enceladus: Cassini ISS observations and models. Astron. J. 148(3), 46 (2014). https://doi.org/10.1088/0004-6256/148/3/46

T.A. Nordheim, K.P. Hand, C. Paranicas, Preservation of potential biosignatures in the shallow subsurface of Europa. Nat. Astron. 2(8), 673-679 (2018). https://doi.org/10.1038/s41550-018-0499-8

A. Palmeiro, M. Martín, I. Crowther, M. Rhodes, Underwater radio frequency communications, in OCEANS 2011 IEEE_Spain (2011), pp. 1-8. https://doi.org/10.1109/Oceans-Spain.2011.6003580

C. Paranicas, J.F. Cooper, H.B. Garrett, R.E. Johnson, S.J. Sturner, Europa's radiation environment and its effects on the surface, in Europa, ed. by R.T. Pappalardo, W.B. McKinnon, K. Khurana (University of Arizona Press, Tucson, 2009), pp. 529-544

V. Parro, G. de Diego-Castilla, J.A. Rodríguez-Manfredi, L.A. Rivas, Y. Blanco-López, E. Sebastián, J. Romeral, C. Compostizo, P.L. Herrero, A. García-Marín, M. Moreno-Paz, M. García-Villadangos, P. 
Cruz-Gil, V. Peinado, J. Martín-Soler, J. Pérez-Mercader, J. Gómez-Elvira, SOLID3: a multiplex antibody microarray-based optical sensor instrument for in situ life detection in planetary exploration. Astrobiology 11(1), 15-28 (2011). https://doi.org/10.1089/ast.2010.0501

K. Philberth, Une méthode pour mesurer les témperatures à l'intérieur d'un inlandsis. C. R. Hebd. Séances Acad. Sci. (Paris) 254(22), 3881-3883 (1962)

C.B. Phillips, R.T. Pappalardo, Europa Clipper mission concept: exploring Jupiter's ocean moon. Eos Trans. AGU 95(20), 165-167 (2014). https://doi.org/10.1002/2014EO200002

C.C. Porco, P. Helfenstein, P.C. Thomas, A.P. Ingersoll, J. Wisdom, R. West, G. Neukum, T. Denk, R. Wagner, T. Roatsch, S. Kieffer, E. Turtle, A. McEwen, T.V. Johnson, J. Rathbun, J. Veverka, D. Wilson, J. Perry, J. Spitale, A. Brahic, J.A. Burns, A.D. DelGenio, L. Dones, C.D. Murray, S. Squyres, Cassini observes the active South pole of Enceladus. Science 311(5766), 1393-1401 (2006). https://doi.org/ 10.1126/science. 1123013

C. Porco, D. DiNino, F. Nimmo, How the geysers, tidal stresses, and thermal emission across the South Polar Terrain of Enceladus are related. Astron. J. 148(3), 45 (2014). https://doi.org/10.1088/ 0004-6256/148/3/45

C.C. Porco, L. Dones, C. Mitchell, Could it be snowing microbes on Enceladus? Assessing conditions in its plume and implications for future missions. Astrobiology 17(9), 876-901 (2017). https://doi.org/ 10.1089/ast.2017.1665

F. Postberg, S. Kempf, J. Schmidt, N. Brilliantov, A. Beinsen, B. Abel, U. Buck, R. Srama, Sodium salts in E-ring ice grains from an ocean below the surface of Enceladus. Nature 459(7250), 1098-1101 (2009). https://doi.org/10.1038/nature08046

F. Postberg, E. Grün, M. Horanyi, S. Kempf, H. Krüger, J. Schmidt, F. Spahn, R. Srama, Z. Sternovsky, M. Trieloff, Compositional mapping of planetary moons by mass spectrometry of dust ejecta. Planet. Space Sci. 59(14), 1815-1825 (2011a). https://doi.org/10.1016/j.pss.2011.05.001

F. Postberg, J. Schmidt, J. Hillier, S. Kempf, R. Srama, A salt-water reservoir as the source of a compositionally stratified plume on Enceladus. Nature 474(7353), 620-622 (2011b). https://doi.org/10.1038/ nature 10175

F. Postberg, R.N. Clark, C.J. Hansen, A.J. Coates, C.M. Dalle Ore, F. Scipioni, M.M. Hedman, J.H. Waite, Plume and surface composition of Enceladus, in Enceladus and the Icy Moons of Saturn (University of Arizona Press, Tucson, 2018a), pp. 129-162. https://doi.org/10.2458/azu_uapress_ 9780816537075-ch007

F. Postberg, N. Khawaja, B. Abel, G. Choblet, C.R. Glein, M.S. Gudipati, B.L. Henderson, H.-W. Hsu, S. Kempf, F. Klenner, G. Moragas-Klostermeyer, B. Magee, L. Nölle, M. Perry, R. Reviol, J. Schmidt, R. Srama, F. Stolz, G. Tobie, M. Trieloff, J.H. Waite, Macromolecular organic compounds from the depths of Enceladus. Nature 558(7711), 564-568 (2018b). https://doi.org/10.1038/s41586-018-0246-4

L.M. Prockter, R.M.C. Lopes, B. Giese, R. Jaumann, R.D. Lorenz, R.T. Pappalardo, G.W. Patterson, P.C. Thomas, E.P. Turtle, R.J. Wagner, Characteristics of icy surfaces. Space Sci. Rev. 153(1), 63-111 (2010). https://doi.org/10.1007/s11214-010-9649-8

K. Reh, L. Spilker, J.I. Lunine, J.H. Waite, M.L. Cable, F. Postberg, K. Clark, Enceladus Life Finder: the search for life in a habitable moon, in 2016 IEEE Aerospace Conference (2016). https://doi.org/ 10.1109/AERO.2016.7500813

L. Roth, J. Saur, K.D. Retherford, D.F. Strobel, P.D. Feldman, M.A. McGrath, F. Nimmo, Transient water vapor at Europa's South pole. Science 343(6167), 171-174 (2014). https://doi.org/10.1126/ science. 1247051

T. Saiki, H. Imamura, M. Arakawa, K. Wada, Y. Takagi, M. Hayakawa, K. Shirai, H. Yano, C. Okamoto, The small carry-on impactor (SCI) and the Hayabusa2 impact experiment. Space Sci. Rev. 208(1), 165-186 (2017). https://doi.org/10.1007/s11214-016-0297-5

J. Schmidt, N. Brilliantov, F. Spahn, S. Kempf, Slow dust in Enceladus' plume from condensation and wall collisions in tiger stripe fractures. Nature 451, 685-688 (2008). https://doi.org/10.1038/nature06491

G. Schubert, F. Sohl, H. Hussmann, Interior of Europa, in Europa, ed. by R.T. Pappalardo, W.B. McKinnon, K.K. Khurana (University of Arizona Press, Tucson, 2009), pp. 353-367

E.M. Schulson, Frictional sliding of cold ice: a fundamental process underlying tectonic activity within icy satellites, in The Science of Solar System Ices, ed. by M.S. Gudipati, J. Castillo-Rogez (Springer, Berlin, 2013), pp. 171-181. https://doi.org/10.1007/978-1-4614-3076-6_6

P.H. Schultz, B. Hermalyn, A. Colaprete, K. Ennico, M. Shirley, W.S. Marshall, The LCROSS cratering experiment. Science 330(6003), 468-472 (2010). https://doi.org/10.1126/science.1187454

Y. Sekine, Y. Takano, H. Yano, R. Funase, K. Takai, M. Ishihara, T. Shibuya, S. Tachibana, K. Kuramoto, H. Yabuta, J. Kimura, Y. Furukawa, Exploration of Enceladus' water-rich plumes toward understanding of chemistry and biology of the interior ocean. Trans. Jpn. Soc. Aeronaut. Space Sci., Aerosp. Technol. Jpn. 12(ists29), Tk_7-Tk_11 (2014). https://doi.org/10.2322/tastj.12.Tk_7 
Y. Sekine, T. Shibuya, F. Postberg, H.-W. Hsu, K. Suzuki, Y. Masaki, T. Kuwatani, M. Mori, P.K. Hong, M. Yoshizaki, S. Tachibana, S. Sirono, High-temperature water-rock interactions and hydrothermal environments in the chondrite-like core of Enceladus. Nat. Commun. 6, 8604 (2015). https://doi.org/ $10.1038 /$ ncomms 9604

P. Serrano, D. Wagner, U. Böttger, J.-P. de Vera, P. Lasch, A. Hermelink, Single-cell analysis of the methanogenic archaeon methanosarcina soligelidi from Siberian permafrost by means of confocal Raman microspectrocopy for astrobiological research. Planet. Space Sci. 98, 191-197 (2014). https://doi.org/10.1016/j.pss.2013.10.002

H. Shiraishi, S. Tanaka, A. Fujimura, H. Hayakawa, The present status of the Japanese penetrator mission: LUNAR-A. Adv. Space Res. 42(2), 386-393 (2008). https://doi.org/10.1016/j.asr.2007.08.022

M.J. Siegert, M.C. Kennicutt, Governance of the exploration of subglacial Antarctica. Front. Environ. Sci. 6, 103 (2018). https://doi.org/10.3389/fenvs.2018.00103

M.J. Siegert, M. Kennicutt, R. Bindschadler, Antarctic Subglacial Aquatic Environments. AGU Geophysical Monograph., vol. 192 (John Wiley \& Sons, New York, 2011)

M.J. Siegert, J.C. Priscu, I.A. Alekhina, J.L. Wadham, W.B. Lyons, Antarctic subglacial lake exploration: first results and future plans. Philos. Trans. R. Soc. Lond. A 374, 20140466 (2016). https://doi.org/ 10.1098/rsta.2014.0466

L.A. Soderblom, S.W. Kieffer, T.L. Becker, R.H. Brown, A.F. Cook, C.J. Hansen, T.V. Johnson, R.L. Kirk, E.M. Shoemaker, Triton's geyser-like plumes: discovery and basic characterization. Science 250(4979), 410-415 (1990). https://doi.org/10.1126/science.250.4979.410

B.S. Southworth, S. Kempf, J. Schmidt, Modeling Europa's dust plumes. Geophys. Res. Lett. 42(24), 10,54110,548 (2015). https://doi.org/10.1002/2015GL066502

B.S. Southworth, S. Kempf, J. Spitale, Surface deposition of the Enceladus plume and the zenith angle of emissions. Icarus 319, 33-42 (2019). https://doi.org/10.1016/j.icarus.2018.08.024

F. Spahn, J. Schmidt, N. Albers, M. Hörning, M. Makuch, M. Seiß, S. Kempf, R. Srama, V. Dikarev, S. Helfert, G. Moragas-Klostermeyer, A.V. Krivov, M. Sremcevic, A.J. Tuzzolino, T. Economou, E. Grün, Cassini dust measurements at Enceladus and implications for the origin of the E ring. Science 311(5766), 1416-1418 (2006). https://doi.org/10.1126/science.1121375

W.B. Sparks, K.P. Hand, M.A. McGrath, E. Bergeron, M. Cracraft, S.E. Deustua, Probing for evidence of plumes on Europa with HST/STIS. Astrophys. J. 829(2), 121 (2016). https://doi.org/10.3847/0004$637 x / 829 / 2 / 121$

W.B. Sparks, B.E. Schmidt, M.A. McGrath, K.P. Hand, J.R. Spencer, M. Cracraft, S.E. Deustua, Active cryovolcanism on Europa? Astrophys. J. Lett. 839(2), L18 (2017). https://doi.org/10.3847/2041$8213 / \mathrm{aa} 67 \mathrm{f} 8$

J.R. Spencer, F. Nimmo, A.P. Ingersoll, T.A. Hurford, E.S. Kite, A.R. Rhoden, J. Schmidt, C.J.A. Howett, Plume origins and plumbing: from ocean to surface, in Enceladus and the Icy Moons of Saturn (University of Arizona Press, Tucson, 2018), pp. 163-174. https://doi.org/10.2458/azu_uapress_ 9780816537075-ch008

R. Srama, T.J. Ahrens, N. Altobelli, S. Auer, J.G. Bradley, M. Burton, V.V. Dikarev, T. Economou, H. Fechtig, M. Görlich, M. Grande, A. Graps, E. Grün, O. Havnes, S. Helfert, M. Horanyi, E. Igenbergs, E.K. Jessberger, T.V. Johnson, S. Kempf, A.V. Krivov, H. Krüger, A. Mocker-Ahlreep, G. Moragas-Klostermeyer, P. Lamy, M. Landgraf, D. Linkert, G. Linkert, F. Lura, J.A.M. McDonnell, D. Möhlmann, G.E. Morfill, M. Müller, M. Roy, G. Schäfer, G. Schlotzhauer, G.H. Schwehm, F. Spahn, M. Stübig, J. Svestka, V. Tschernjawski, A.J. Tuzzolino, R. Wäsch, H.A. Zook, The Cassini Cosmic Dust Analyzer (Springer, Berlin, 2004), pp. 465-518. https://doi.org/10.1007/978-1-4020-2774-1_7

K. Stephan, R. Jaumann, R. Wagner, Geology of icy bodies, in The Science of Solar System Ices, ed. by M.S. Gudipati, J. Castillo-Rogez (Springer, Berlin, 2013), pp. 279-367. https://doi.org/10.1007/9781-4614-3076-6_10

W. Stone, B. Hogan, V. Siegel, J. Harman, C. Flesher, E. Clark, O. Pradhan, A. Gasiewski, S. Howe, T. Howe, Project VALKYRIE: laser-powered cryobots and other methods for penetrating deep ice on ocean worlds, in Outer Solar System: Prospective Energy and Material Resources, ed. by V. Badescu, K. Zacny (Springer, Berlin, 2018a), pp. 47-165. https://doi.org/10.1007/978-3-319-73845-1_4

W. Stone, K. Richmond, C. Flesher, B. Hogan, V. Siegel, Sub-ice autonomous underwater vehicle architectures for ocean world exploration and life search, in Outer Solar System: Prospective Energy and Material Resources, ed. by V. Badescu, K. Zacny (Springer, Berlin, 2018b), pp. 429-541. https://doi.org/10.1007/978-3-319-73845-1_10

P.G. Talalay, V.S. Zagorodnov, A.N. Markov, M.A. Sysoev, J. Hong, Recoverable autonomous sonde (RECAS) for environmental exploration of Antarctic subglacial lakes: general concept. Ann. Glaciol. 55(65), 23-30 (2014). https://doi.org/10.3189/2014AoG65A003

A. Tengberg, J. Hovdenes, H.J. Andersson, O. Brocandel, R. Diaz, D. Hebert, T. Arnerich, C. Huber, A. Körtzinger, A. Khripounoff, F. Rey, C. Rönning, J. Schimanski, S. Sommer, A. Stangelmayer, Evalu- 
ation of a lifetime-based optode to measure oxygen in aquatic systems. Limnol. Oceanogr., Methods 4(2), 7-17 (2006). https://doi.org/10.4319/lom.2006.4.7

G. Tobie, Planetary science: Enceladus' hot springs. Nature 519(7542), 162-163 (2015). https://doi.org/ $10.1038 / 519162 \mathrm{a}$

M. Treffer, N. Kömle, G. Kargl, E. Kaufmann, S. Ulamec, J. Biele, A. Ivanov, O. Funke, Preliminary studies concerning subsurface probes for the exploration of icy planetary bodies. Planet. Space Sci. 54(6), 621634 (2006). https://doi.org/10.1016/j.pss.2006.02.001

S.K. Trumbo, M.E. Brown, K.P. Hand, Sodium chloride on the surface of Europa. Sci. Adv. 5(6), eaaw7123 (2019). https://doi.org/10.1126/sciadv.aaw7123

P. Tsou, D.E. Brownlee, C.P. McKay, A.D. Anbar, H. Yano, K. Altwegg, L.W. Beegle, R. Dissly, N.J. Strange, I. Kanik, LIFE: life investigation for Enceladus a sample return mission concept in search for evidence of life. Astrobiology 12(8), 730-742 (2012). https://doi.org/10.1089/ast.2011.0813

H. Tüg, Private communication (2002)

H. Tüg, M. Damm, Rechnergesteuerte Schmelzsonde zur Ermittlung unterschiedlicher Messparameter im Eisbereich (2003). Patentschrift DE10164648C1

S. Ulamec, J. Biele, J. Drescher, A. Ivanov, A melting probe with applications on Mars, Europa and Antarctica, in 56th International Astronautical Congress (2005). https://doi.org/10.2514/6.IAC-05-A1.7.08. IAC-A1.7.08

S. Ulamec, J. Biele, O. Funke, M. Engelhardt, Access to glacial and subglacial environments in the solar system by melting probe technology. Rev. Environ. Sci. Biotechnol. 6(1), 71-94 (2007). https://doi.org/ 10.1007/s11157-006-9108-X

S. Ulamec, J. Biele, E. Trollope, How to survive a lunar night. Planet. Space Sci. 58(14), 1985-1995 (2010). https://doi.org/10.1016/j.pss.2010.09.024

United Nations Office for Outer Space Affairs. Treaty on principles governing the activities of states in the exploration and use of outer space, including the moon and other celestial bodies (1966). http://www.unoosa.org/oosa/en/ourwork/spacelaw/treaties/introouterspacetreaty.html

J.H. Waite, W.S. Lewis, W.T. Kasprzak, V.G. Anicich, B.P. Block, T.E. Cravens, G.G. Fletcher, W.-H. Ip, J.G. Luhmann, R.L. McNutt, H.B. Niemann, J.K. Parejko, J.E. Richards, R.L. Thorpe, E.M. Walter, R.V. Yelle, The Cassini Ion and Neutral Mass Spectrometer (INMS) Investigation (Springer, Berlin, 2004), pp. 113-231. https://doi.org/10.1007/978-1-4020-2774-1_2

J.H. Waite, W.S. Lewis, B.A. Magee, J.I. Lunine, W.B. McKinnon, C.R. Glein, O. Mousis, D.T. Young, T. Brockwell, J. Westlake, M.-J. Nguyen, B.D. Teolis, H.B. Niemann, R.L. McNutt, M. Perry, W.-H. Ip et al., Liquid water on Enceladus from observations of ammonia and ${ }^{40} \mathrm{Ar}$ in the plume. Nature 460(7254), 487 (2009). https://doi.org/10.1038/nature08153

J.H. Waite, C.R. Glein, R.S. Perryman, B.D. Teolis, B.A. Magee, G. Miller, J. Grimes, M.E. Perry, K.E. Miller, A. Bouquet, J.I. Lunine, T. Brockwell, S.J. Bolton, Cassini finds molecular hydrogen in the Enceladus plume: evidence for hydrothermal processes. Science 356(6334), 155-159 (2017). https:// doi.org/10.1126/science.aai8703

C. Waldmann, T.M. Kier, W.S. Kirkwood, S. Meckel, Performance data of a pneumatic variable buoyancy engine for a newly designed underwater glider, in OCEANS 2016 MTS/IEEE Monterey, Monerey, CA, USA (2016), pp. 1-3. https://doi.org/10.1109/OCEANS.2016.7761225

D. Walsh, The Bathyscaph TRIESTE, technological and operational aspects, 1958-1961. Technical report, U.S. Navy Electronics Laboratory (1962)

D.P. Winebrenner, W.T. Elam, V. Miller, M. Carpenter, A thermal ice-melt probe for exploration of Earthanalogs to Mars, Europa and Enceladus, in Lunar and Planetary Science Conference, vol. 44 (2013), p. 2986

M. Wirtz, M. Hildebrand, IceShuttle Teredo: an ice-penetrating robotic system to transport an exploration AUV into the ocean of Jupiter's moon Europa, in 67th International Astronautical Congress, Guadalajara, Mexico (2016). IAC-16-A3.5.2

S.K. Yeoh, T.A. Chapman, D.B. Goldstein, P.L. Varghese, L.M. Trafton, On understanding the physics of the Enceladus South polar plume via numerical simulation. Icarus 253, 205-222 (2015). https:// doi.org/10.1016/j.icarus.2015.02.020

M. Yücel, A.D. Beaton, M. Dengler, M.C. Mowlem, F. Sohl, S. Sommer, Nitrate and nitrite variability at the seafloor of an oxygen minimum zone revealed by a novel microfluidic in-situ chemical sensor. PLoS ONE 10(7), 1-16 (2015). https://doi.org/10.1371/journal.pone.0132785

K. Zacny, G. Paulsen, Y. Bar-Cohen, L. Beegle, S. Sherrit, M. Badescu, B. Mellerowicz, O. Rzepiejewska, J. Craft, S. Sadick, F. Corsetti, Y. Ibarra, X. Bao, H.J. Lee, B. Abbey, Wireline deep drill for exploration of Mars, Europa, and Enceladus, in 2013 IEEE Aerospace Conference (2013), pp. 1-14. https://doi.org/10.1109/AERO.2013.6497189

K. Zacny, M. Shara, G. Paulsen, B. Mellerowicz, J. Spring, A. Ridilla, H. Nguyen, K. Ridilla, M. Hedlund, R. Sharpe, J. Bowsher, N. Hoisington, S. Gorevan, J. Abrashkin, L. Cubrich, M. Reichenbach, Devel- 
opment of a Planetary Deep Drill (American Society of Civil Engineers, Reston, 2016), pp. 256-266. https://doi.org/10.1061/9780784479971.027

K. Zacny, J. Mueller, T. Costa, T. Cwik, A. Gray, W. Zimmerman, P. Chow, F. Rehnmark, G. Adams, SLUSH: Europa hybrid deep drill, in 2018 IEEE Aerospace Conference (2018), pp. 1-14. https://doi.org/10.1109/AERO.2018.8396596

W. Zimmerman, R. Bonitz, J.F. Cryobot, An ice penetrating robotic vehicle for Mars and Europa, in Proceedings of the IEEE Aerospace Conference 2001, Big Sky, MT (2001a), pp. 1/311-1/323

W. Zimmerman, S. Bryant, J. Zitzelberger, B. Nesmith, A radioisotope powered cryobot for penetrating the Europan ice shell, in Space Technology and Application International Forum 2001, New Mexico (2001b). https://doi.org/10.1063/1.1357997 